\title{
Total Synthesis of Asimicin via Highly Stereoselective [3+2] Annulation Reactions of Substituted Allylsilanes
}

\author{
Jennifer M. Tinsley and William R. Roush* \\ Department of Chemistry, University of Michigan, Ann Arbor, MI, 48109 \\ e-mail: roush@umich.edu
}

\section{Supporting Information}

Part I. Experimental procedures and tabulated spectroscopic data for all new compounds. 
General Experimental Details. All reaction solvents were purified before use. Tetrahydrofuran, dichloromethane, toluene, and diethyl ether were purified by passing through a solvent column composed of activated A-1 alumina. $\mathrm{BF}_{3} \cdot \mathrm{OEt}_{2}$ and $\mathrm{SnCl}_{4}$ were purified by fractional distillation and stored under nitrogen. Unless indicated, all other reagents and solvents were used as purchased without further purification.

Proton nuclear magnetic resonance $\left({ }^{1} \mathrm{H}\right.$ NMR) spectra were conducted on a Varian VXR400 spectrometer at $400 \mathrm{MHz}$ or on an Inova-500 spectrometer at $500 \mathrm{MHz}$. Carbon-13 nuclear magnetic resonance $\left({ }^{13} \mathrm{C} \mathrm{NMR}\right)$ spectra were recorded on the aforementioned instruments at 100 $\mathrm{MHz}$ and $125 \mathrm{MHz}$, respectively. The proton signal of residual non-deuterated solvent $(\square 7.26 \mathrm{ppm}$ for $\mathrm{CHCl}_{3}$ ) was used as an internal reference for ${ }^{1} \mathrm{H}$ NMR spectra. For ${ }^{13} \mathrm{C}$ NMR spectra, chemical shifts are reported relative to the $\square 77.2 \mathrm{ppm}$ resonance of $\mathrm{CHCl}_{3}$. Coupling constants are reported in Hz. Infrared (IR) spectra were recorded as films on a Perkin-Elmer Spectrum 1000 FTIR. Optical rotations were measured on a Rudolph Autopol III polarimeter using a quartz cell with 1 $\mathrm{mL}$ capacity and a $10 \mathrm{~cm}$ path length. Mass spectra were recorded on a ZVG 70-250-S spectrometer manufactured by Micromass Corp. (Manchester, UK). Optical rotations were measured on a Rudolph Autopol III polarimeter using a $1 \mathrm{~mL}$ capacity quartz cell with a $10 \mathrm{~cm}$ path length. Elemental analyses were performed by Atlantic Microlab, Inc. in Norcross, Georgia.

Analytical thin layer chromatography (TLC) was performed on Kieselgel $60 \mathrm{~F}_{254}$ glass plates pre-coated with a $0.25 \mathrm{~mm}$ thickness of silica gel. The TLC plates were visualized with UV light and/or by staining with Hanessian solution (ceric sulfate and ammonium molybdate in aqueous sulfuric acid). Column chromatography was generally performed using Kieselgel 60 (230-400 mesh) silica gel, typically using a 50-100:1 weight ratio of silica gel to crude product.

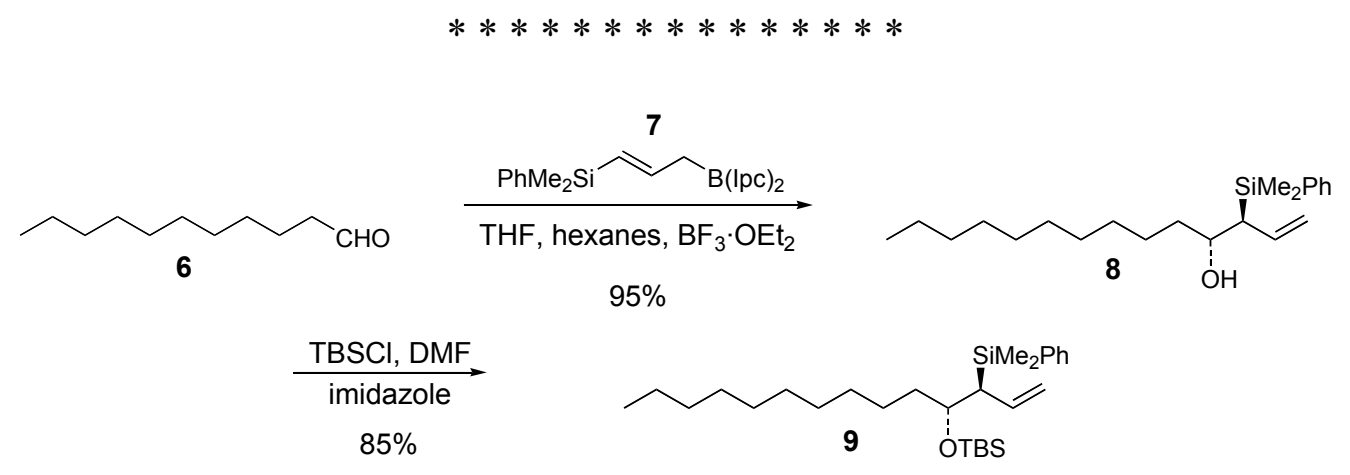

(3S,4R)-3-(Dimethylphenylsilanyl)-4-hydroxy-tridec-1-ene (8). To a solution of $\mathrm{KO} t \mathrm{Bu}$ $(2.3 \mathrm{~g}, 20.6 \mathrm{mmol})$ in $\mathrm{THF}(40 \mathrm{~mL})$ at $-78^{\circ} \mathrm{C}$ was added allyldimethylphenylsilane $(4.0 \mathrm{~g}, 22.7$ $\mathrm{mmol}$ ). The mixture was stirred for $5 \mathrm{~min}$, then $n$-BuLi (2.4 M in hexanes, $8.6 \mathrm{~mL}, 20.6 \mathrm{mmol})$ was added slowly via syringe over $5 \mathrm{~min}$. The reaction was stirred at $-78{ }^{\circ} \mathrm{C}$ for $10 \mathrm{~min}$ and then 
warmed to $-45^{\circ} \mathrm{C}$ and stirred for $2 \mathrm{~h}$. The reaction was recooled to $-78{ }^{\circ} \mathrm{C}$ and (-)-Ipc $\mathrm{BOMe}_{2}(6.5 \mathrm{~g}$, $20.6 \mathrm{mmol}$ ) was added as a solution in THF $(26 \mathrm{~mL})$ slowly over $5 \mathrm{~min}$. The reaction was stirred for $30 \mathrm{~min}$ and then $\mathrm{BF}_{3} \cdot \mathrm{OEt}_{2}(3.9 \mathrm{~g}, 27.4 \mathrm{mmol})$ was added in one portion. After $5 \mathrm{~min}$, undecanal (4.2 g, $24.7 \mathrm{mmol})$ was added as a solution in hexanes $(40 \mathrm{~mL})$ slowly over $5 \mathrm{~min}$. The reaction was stirred at $-78{ }^{\circ} \mathrm{C}$ for $4 \mathrm{~h}$ and then diluted with $\mathrm{KOH} / \mathrm{KH}_{2} \mathrm{PO}_{4}$ buffer $\left(1 \mathrm{M}\right.$ solution of $\mathrm{KH}_{2} \mathrm{PO}_{4}$, adjusted to pH 6 with $\mathrm{KOH}, 20 \mathrm{~mL})$ and warmed to room temperature. $\mathrm{H}_{2} \mathrm{O}_{2}(35 \%, 3 \mathrm{~mL})$ was added and the two-phase mixture was stirred at ambient temperature for $16 \mathrm{~h}$. The reaction mixture was partitioned between $\mathrm{H}_{2} \mathrm{O}$ and 1:1 hexanes- $\mathrm{Et}_{2} \mathrm{O}$. The organic layer was dried over $\mathrm{Na}_{2} \mathrm{SO}_{4}$, concentrated, and purified by chromatography $\left(\mathrm{SiO}_{2}, 5 \% \mathrm{Et}_{2} \mathrm{O}\right.$-hexanes) to give $6.8 \mathrm{~g}(95 \%)$ of allylsilane 8 as a colorless oil: $[\square]_{\mathrm{D}}{ }^{23.0}=-0.7\left(\mathrm{c} 1.5, \mathrm{CHCl}_{3}\right) ;{ }^{1} \mathrm{H} \mathrm{NMR}\left(500 \mathrm{MHz}, \mathrm{CDCl}_{3}\right) \square 7.57-$ $7.54(\mathrm{~m}, 2 \mathrm{H}), 7.40-7.34(\mathrm{~m}, 3 \mathrm{H}), 5.84(\mathrm{dt}, J=17.0,10.5 \mathrm{~Hz}, 1 \mathrm{H}), 5.06(\mathrm{dd}, J=10.5,2.0 \mathrm{~Hz}, 1 \mathrm{H})$, $4.91(\mathrm{dd}, J=17.5,2.0 \mathrm{~Hz}, 1 \mathrm{H}), 3.76-3.60(\mathrm{~m}, 1 \mathrm{H}), 1.91$ (dd, $J=10.5,4.5 \mathrm{~Hz}, 1 \mathrm{H}), 1.56(\mathrm{bs}, 1 \mathrm{H})$, $1.44-1.16(\mathrm{~m}, 18 \mathrm{H}), 0.89(\mathrm{t}, J=7.0 \mathrm{~Hz}, 3 \mathrm{H}), 0.37(\mathrm{~s}, 3 \mathrm{H}), 0.34(\mathrm{~s}, 3 \mathrm{H}) ;{ }^{13} \mathrm{C} \mathrm{NMR}(125 \mathrm{MHz}$, $\left.\mathrm{CDCl}_{3}\right) \square 138.3,135.5,134.3,129.3,128.0,115.7,71.7,42.3,37.4,32.2,29.9,29.8,29.8,29.8$, 29.6, 26.0, 23.0, 14.4, -3.1, -3.7; IR (thin film) 3468, 3070, 2956, 2930, 2854, 1624, 1466, 1428, $1248,1113,1000,898,833,814,792,732,700,653 \mathrm{~cm}^{-1}$; HRMS calcd for $\mathrm{C}_{22} \mathrm{H}_{38} \mathrm{OSi}, 833.5157$ $\mathrm{m} / z(\mathrm{M}+\mathrm{Na})^{+}$; observed $833.5178 \mathrm{~m} / z$. Anal. Calcd for $\mathrm{C}_{22} \mathrm{H}_{38} \mathrm{OSi}$; C, 74.01; H, 9.69. Found: C, 73.84; H, 9.68.

(3S,4R)-3-(Dimethylphenylsilanyl)-4-(tert-butyldimethylsilanyloxy)-tridec-1-ene (9). To a solution of allylsilane $8(6.1 \mathrm{~g}, 17.5 \mathrm{mmol})$ in DMF $(17.5 \mathrm{~mL})$ was added TBSCl $(5.3 \mathrm{~g}, 35.0$ mmol) and imidazole $(3.6 \mathrm{~g}, 52.5 \mathrm{mmol})$ at ambient temperature. The reaction flask was flushed with nitrogen, sealed with a septum, and heated to $50{ }^{\circ} \mathrm{C}$ for $48 \mathrm{~h}$. The mixture was cooled to ambient temperature and partitioned between $\mathrm{H}_{2} \mathrm{O}$ and hexanes. The organic layer was dried over $\mathrm{MgSO}_{4}$, and concentrated. The crude product was purified by chromatography $\left(\mathrm{SiO}_{2}\right.$, hexanes) to give $6.7 \mathrm{~g}(85 \%)$ of allylsilane 9 as a colorless oil: $[\square]_{\mathrm{D}}{ }^{23.0}=-2.9\left(\mathrm{c} 1.2, \mathrm{CHCl}_{3}\right) ;{ }^{1} \mathrm{H} \mathrm{NMR}(400$ $\left.\mathrm{MHz}, \mathrm{CDCl}_{3}\right) \square 7.49-7.43$ (m, 2H), 7.31-7.26 (m, 3H), 5.80 (dt, J=17.2, $\left.10.8 \mathrm{~Hz}, 1 \mathrm{H}\right), 4.89$ (dd, $J$ $=10.0,2.0 \mathrm{~Hz}, 1 \mathrm{H}), 4.69(\mathrm{dd}, J=17.2,2.0 \mathrm{~Hz}, 1 \mathrm{H}), 3.82-3.76(\mathrm{~m}, 1 \mathrm{H}), 1.96(\mathrm{dd}, J=10.4,3.6 \mathrm{~Hz}$, $1 \mathrm{H}), 1.50-1.41(\mathrm{~m}, 1 \mathrm{H}), 1.38-1.00(\mathrm{~m}, 20 \mathrm{H}), 0.83(\mathrm{~s}, 9 \mathrm{H}), 0.30(\mathrm{~s}, 3 \mathrm{H}), 0.35(\mathrm{~s}, 3 \mathrm{H}),-0.04(\mathrm{~s}, 3 \mathrm{H}),-$ $0.06(\mathrm{~s}, 3 \mathrm{H}) ;{ }^{13} \mathrm{C} \mathrm{NMR}\left(100 \mathrm{MHz}, \mathrm{CDCl}_{3}\right) \square 139.0,136.2,134.3,128.9,127.7,114.5,73.6,40.8$, $37.0,32.1,29.8,29.8,29.5,26.3,25.9,25.6,22.9,18.4,14.3,-2.9,-3.5,-3.5,-3.7$; IR (thin film) 2955, 2927, 2856, 1253, 1063, $835 \mathrm{~cm}^{-1}$; HRMS calcd for $\mathrm{C}_{28} \mathrm{H}_{52} \mathrm{OSi}_{2}, 483.3454 \mathrm{~m} / z(\mathrm{M}+\mathrm{Na})^{+}$; observed $483.3451 \mathrm{~m} / \mathrm{z}$. 


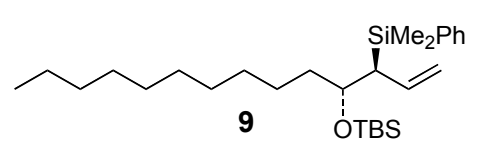

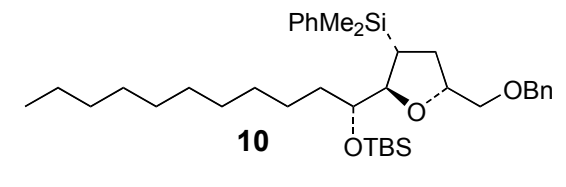

$93 \%$

(2S, 3R, 5R)-5-(Benzyloxymethyl)-2-[(1R)-1-(tert-butyldimethylsilanyloxy)-undecyl]-3(dimethylphenylsilanyl)-tetrahydrofuran (10). To a $-45^{\circ} \mathrm{C}$ solution of allylsilane $9(1.0 \mathrm{~g}, 2.2$ mmol), $\square$-benzyloxyacetaldehyde (400 mg, $2.7 \mathrm{mmol}$ ), and flame-dried powdered $4 \AA$ molecular sieves $(500 \mathrm{mg})$ in $\mathrm{CH}_{2} \mathrm{Cl}_{2}(4.4 \mathrm{~mL})$ was added $\mathrm{SnCl}_{4}(280 \mathrm{mg}, 1.1 \mathrm{mmol})$ dropwise from a syringe over 2 min. The reaction mixture was stirred at $-45^{\circ} \mathrm{C}$ for $20 \mathrm{~h}$ and then quenched with $\mathrm{Et}_{3} \mathrm{~N}(1$ $\mathrm{mL})$ and warmed to ambient temperature. The mixture was diluted with hexanes $(5 \mathrm{~mL}), \mathrm{Et}_{2} \mathrm{O}(5$ $\mathrm{mL})$, and saturated $\mathrm{NaHCO}_{3}(5 \mathrm{~mL})$ and stirred for $24 \mathrm{~h}$. The layers were separated and the aqueous layer was washed with 1:1 hexanes-Et $\mathrm{O}_{2} \mathrm{O}(50 \mathrm{~mL})$. The combined organic layers were dried over $\mathrm{MgSO}_{4}$, concentrated, and purified by chromatography $\left(\mathrm{SiO}_{2}, 5 \% \mathrm{Et}_{2} \mathrm{O}\right.$-hexanes) to give $1.2 \mathrm{~g}(93 \%)$ of tetrahydrofuran 10 as a colorless oil: $[\square]_{\mathrm{D}}{ }^{23.0}=-0.8\left(\mathrm{c} 2.4, \mathrm{CHCl}_{3}\right) ;{ }^{1} \mathrm{H} \mathrm{NMR}(500$ $\left.\mathrm{MHz}, \mathrm{CDCl}_{3}\right) \square 7.51-7.48(\mathrm{~m}, 2 \mathrm{H}), 7.39-7.26(\mathrm{~m}, 8 \mathrm{H}), 4.60-4.52(\mathrm{~m}, 2 \mathrm{H}), 4.10-4.04(\mathrm{~m}, 1 \mathrm{H}), 3.95$ $(\mathrm{dd}, J=9.0,2.0 \mathrm{~Hz}, 1 \mathrm{H}), 3.53\left(\mathrm{~A}\right.$ of $\left.\mathrm{ABX}, J_{\mathrm{AB}}=10.5 \mathrm{~Hz}, J_{\mathrm{AX}}=5.5 \mathrm{~Hz}, 1 \mathrm{H}\right), 3.45\left(\mathrm{~B}\right.$ of $\mathrm{ABX}, J_{\mathrm{AB}}$ $\left.=10.0 \mathrm{~Hz}, J_{\mathrm{BX}}=5.0 \mathrm{~Hz}, 1 \mathrm{H}\right), 3.28-3.24(\mathrm{~m}, 1 \mathrm{H}), 2.07-2.01(\mathrm{~m}, 1 \mathrm{H}), 1.77-1.62(\mathrm{~m}, 2 \mathrm{H}), 1.53-1.46$ $(\mathrm{m}, 2 \mathrm{H}), 1.39-1.15(\mathrm{~m}, 16 \mathrm{H}), 0.90(\mathrm{~s}, 12 \mathrm{H}), 0.34(\mathrm{~s}, 3 \mathrm{H}), 0.33(\mathrm{~s}, 3 \mathrm{H}), 0.02(\mathrm{~s}, 3 \mathrm{H}), 0.01(\mathrm{~s}, 3 \mathrm{H}) ;{ }^{13} \mathrm{C}$ NMR $\left(125 \mathrm{MHz}, \mathrm{CDCl}_{3}\right) \square 138.9,138.2,134.1,129.4,128.5,128.1,128.0,127.7,83.1,78.8,75.1$, 73.5, 72.9, 34.9, 33.5, 32.2, 30.1, 29.9, 29.9, 29.7, 26.8, 26.4, 26.2, 23.0, 18.5, 14.4, -3.7, -3.8, -4.1, -4.1; IR (thin film) 2954, 2920, 2855, 1462, 1428, 1360, 1251, 1112, 835, 773, 734, $698 \mathrm{~cm}^{-1}$; HRMS calcd for $\mathrm{C}_{37} \mathrm{H}_{62} \mathrm{O}_{3} \mathrm{Si}_{2}, 633.4135 \mathrm{~m} / z(\mathrm{M}+\mathrm{Na})^{+}$; observed $633.4153 \mathrm{~m} / z$. Anal. Calcd for $\mathrm{C}_{37} \mathrm{H}_{62} \mathrm{O}_{3} \mathrm{Si}_{2} ; \mathrm{C}, 72.73 ; \mathrm{H}, 10.23$. Found: C, 72.84; H, 10.21.
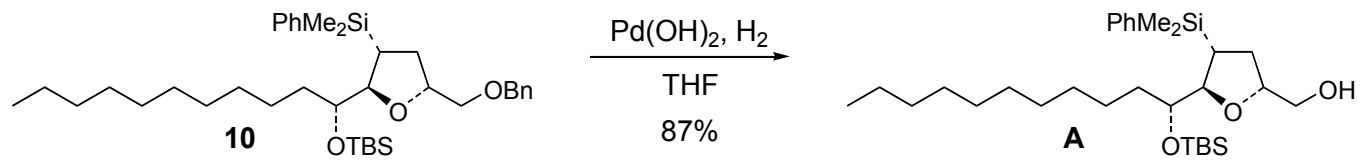

(2R，4R，5S)-[5-[(1R)-1-(tert-Butyldimethylsilanyloxy)-undecyl]-4-(dimethylphenylsilanyl)-tetrahydrofuran-2-yl]-methanol (A): To a solution of tetrahydrofuran 10 (520 mg, 0.8 mmol) in THF $(5 \mathrm{~mL})$ was added $10 \% \operatorname{Pd}(\mathrm{OH})_{2}(250 \mathrm{mg})$. The reaction flask was evacuated and purged with $\mathrm{H}_{2}$ three times and then the reaction was stirred at ambient temperature under a hydrogen atmosphere for $2 \mathrm{~h}$. The reaction flask was then evacuated and purged with nitrogen three times. The catalyst was removed by filtration through Celite. The filtrate was concentrated and the crude product purified by chromatography $\left(\mathrm{SiO}_{2}, 10 \%\right.$ EtOAc-hexanes) to give $380 \mathrm{mg}$ (87\%) of $\mathbf{A}$ 
as a colorless oil: $[\square]_{\mathrm{D}}{ }^{23.0}=-13.3\left(\mathrm{c} 1.7, \mathrm{CHCl}_{3}\right) ;{ }^{1} \mathrm{H} \mathrm{NMR}\left(500 \mathrm{MHz}, \mathrm{CDCl}_{3}\right) \square 7.52-7.48(\mathrm{~m}, 2 \mathrm{H})$, 7.39-7.34 (m, 3H), 4.02-3.96 (m, 1H), $3.94(\mathrm{dd}, J=8.5,2.0 \mathrm{~Hz}, 1 \mathrm{H}), 3.73$ (dd, $J=11.5,3.0 \mathrm{~Hz}$, 1H), 3.45 (dd, $J=12.0,4.5$ Hz, 1H), 3.26-3.20 (m, 1H), 1.95-1.89 (m, 1H), 1.81-1.74 (m, 1H), 1.68 $1.56(\mathrm{~m}, 3 \mathrm{H}), 1.37-1.13(\mathrm{~m}, 20 \mathrm{H}), 0.89(\mathrm{~s}, 9 \mathrm{H}), 0.34(\mathrm{~s}, 6 \mathrm{H}), 0.02(\mathrm{~s}, 3 \mathrm{H}), 0.00(\mathrm{~s}, 3 \mathrm{H}) ;{ }^{13} \mathrm{C} \mathrm{NMR}$ $\left(125 \mathrm{MHz}, \mathrm{CDCl}_{3}\right) \square 137.9,134.0,129.5,128.1,83.0,80.0,75.0,64.5,34.9,32.2,31.5,30.0,29.9$, 29.6, 27.0, 26.3, 26.1, 23.0, 18.4, 14.4, -3.7, -4.1, -4.2, -4.2; IR (thin film) 3448, 2955, 2925, 2855, 1462, 1428, 1376, 1252, 1112, 1067, 836, 773, 734, $700 \mathrm{~cm}^{-1}$; HRMS calcd for $\mathrm{C}_{30} \mathrm{H}_{56} \mathrm{O}_{3} \mathrm{Si}_{2}$, $543.3666 \mathrm{~m} / z(\mathrm{M}+\mathrm{Na})^{+}$; observed $543.3676 \mathrm{~m} / z$. Anal. Calcd for $\mathrm{C}_{30} \mathrm{H}_{56} \mathrm{O}_{3} \mathrm{Si}_{2} ; \mathrm{C}, 69.17 ; \mathrm{H}, 10.84$. Found: C, 69.20; H, 11.09.
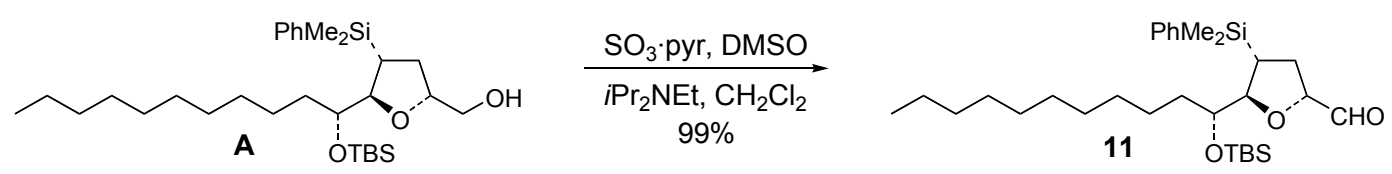

(2R, 4R, 5S)-5-[(1R)-1-(tert-Butyldimethylsilanyloxy)-undecyl]-4-(dimethylphenylsilanyl)-tetrahydrofuran-2-carbaldehyde (11). To a solution of alcohol A (260 mg, $0.5 \mathrm{mmol})$, diisopropyl ethyl amine (320 mg, $2.5 \mathrm{mmol}$ ), and DMSO (390 mg, $5.0 \mathrm{mmol})$ in $\mathrm{CH}_{2} \mathrm{Cl}_{2}(2.5 \mathrm{~mL})$ at $0{ }^{\circ} \mathrm{C}$ was added $\mathrm{SO}_{3}$-pyridine complex $(240 \mathrm{mg}, 1.5 \mathrm{mmol})$ as a solid in one portion. The reaction was stirred at $0{ }^{\circ} \mathrm{C}$ for $1 \mathrm{~h}$. The reaction was quenched with an aqueous solution of saturated $\mathrm{Na}_{2} \mathrm{~S}_{2} \mathrm{O}_{3}(5 \mathrm{~mL})$ and warmed to ambient temperature. The aqueous layer was extracted with EtOAc $(2 \times 75 \mathrm{~mL})$. The combined organic layers were dried over $\mathrm{MgSO}_{4}$, concentrated, and purified by chromatography $\left(\mathrm{SiO}_{2}, 10 \% \mathrm{Et}_{2} \mathrm{O}\right.$-hexanes) to give $255 \mathrm{mg}(99 \%)$ of aldehyde 11 as a colorless oil: $[\square]_{\mathrm{D}}{ }^{23.0}=46.7$ (c 3.9, $\left.\mathrm{CHCl}_{3}\right) ;{ }^{1} \mathrm{H} \mathrm{NMR}\left(500 \mathrm{MHz}, \mathrm{CDCl}_{3}\right) \square 9.55(\mathrm{~d}, J=2.5 \mathrm{~Hz}, 1 \mathrm{H}), 7.50-7.46$ (m, 2H), 7.42-7.35 (m, 3H), 4.21-4.16 (m, 1H), $4.08(\mathrm{dd}, J=8.5,1.5 \mathrm{~Hz}, 1 \mathrm{H}), 3.27-3.22(\mathrm{~m}, 1 \mathrm{H})$, 2.25-2.19 (m, 1H), 1.85-1.78 (m, 1H), 1.75-1.62 (m, 2H), 1.45-1.37 (m, 1H), 1.36-1.13 (m, 19H), 0.89 (s, 9H), 0.36 (s, 6H), $0.01(\mathrm{~s}, 3 \mathrm{H}), 0.00(\mathrm{~s}, 3 \mathrm{H}) ;{ }^{13} \mathrm{C} \mathrm{NMR}\left(125 \mathrm{MHz}, \mathrm{CDCl}_{3}\right) \square 202.9,137.1$, 134.0, 129.7, 128.3, 84.3, 83.9, 74.6, 35.0, 32.2, 32.1, 30.0, 29.9, 29.8, 29.6, 26.8, 26.2, 26.0, 23.0, 18.4, 14.5, -3.6, -4.1, -4.2, -4.2; IR (thin film) 3070, 2955, 2920, 2856, 1736, 1463, 1428, 1376, 1253, 1113, 1067, 1006, 927, 884, 836, 774, 735, 700, 670, $648 \mathrm{~cm}^{-1}$; HRMS calcd for $\mathrm{C}_{30} \mathrm{H}_{54} \mathrm{O}_{3} \mathrm{Si}_{2}$, $573.3771 \mathrm{~m} / \mathrm{z}(\mathrm{M}+\mathrm{Na})^{+}$; observed $573.3778 \mathrm{~m} / \mathrm{z}$. Anal. Calcd for $\mathrm{C}_{30} \mathrm{H}_{54} \mathrm{O}_{3} \mathrm{Si}_{2} ; \mathrm{C}, 69.44 ; \mathrm{H}, 10.49$. Found: C, 69.42; H, 10.54 . 


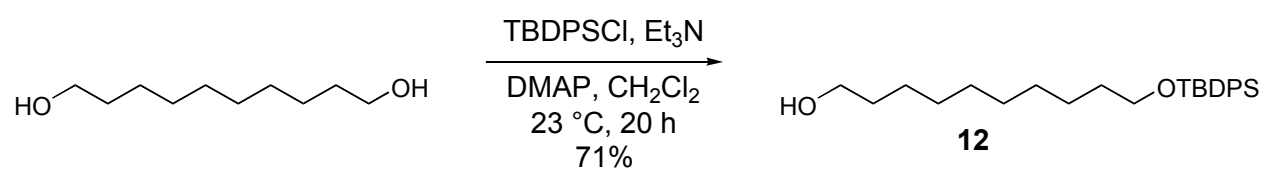

10-(tert-Butyldiphenylsilanyloxy)-decan-1-ol (12). To a suspension of commercially available 1,10-decanediol (10.0 g, $57.4 \mathrm{mmol})$, triethylamine $(4.0 \mathrm{~mL}, 28.7 \mathrm{mmol})$, and DMAP (230 $\mathrm{mg}, 1.9 \mathrm{mmol})$ in $\mathrm{CH}_{2} \mathrm{Cl}_{2}(500 \mathrm{~mL})$ was added TBDPSCl $(5.0 \mathrm{ml}, 19.1 \mathrm{mmol})$ dropwise over 10 min. The reaction mixture was stirred at room temperature for $20 \mathrm{~h}$ and then half of the $\mathrm{CH}_{2} \mathrm{Cl}_{2}$ was removed at reduced pressure. The remaining suspension was diluted with $250 \mathrm{~mL}$ of hexanes and the resulting precipitate was removed by filtration. The filtrate was concentrated and the crude product was purified by chromatography $\left(\mathrm{SiO}_{2}, 10 \%\right.$ to $25 \%$ EtOAc-hexanes) to give $5.6 \mathrm{~g}(71 \%)$ of the monoprotected diol 12: ${ }^{1} \mathrm{H}$ NMR (400 $\left.\mathrm{MHz} \mathrm{CDCl}_{3}\right) \square 7.66-7.61(\mathrm{~m}, 4 \mathrm{H}), 7.41-7.31(\mathrm{~m}, 6 \mathrm{H})$, $3.61(\mathrm{t}, J=6.4 \mathrm{~Hz}, 2 \mathrm{H}), 3.60(\mathrm{t}, J=6.4 \mathrm{~Hz}, 2 \mathrm{H}), 1.57-1.47(\mathrm{~m}, 4 \mathrm{H}), 1.35-1.18(\mathrm{~m}, 13 \mathrm{H}), 1.01(\mathrm{~s}$, 9H); ${ }^{13} \mathrm{C}$ NMR (100 MHz, $\left.\mathrm{CDCl}_{3}\right) \square$ 135.8, 134.4, 129.7, 127.8, 64.2, 63.3, 33.0, 32.8, 29.7, 29.6, 27.1, 26.0, 25.9, 19.4; HRMS calcd for $\mathrm{C}_{26} \mathrm{H}_{40} \mathrm{O}_{2} \mathrm{Si}, 435.2695 \mathrm{~m} / z(\mathrm{M}+\mathrm{Na})^{+}$; observed 435.2688 $m / z$.

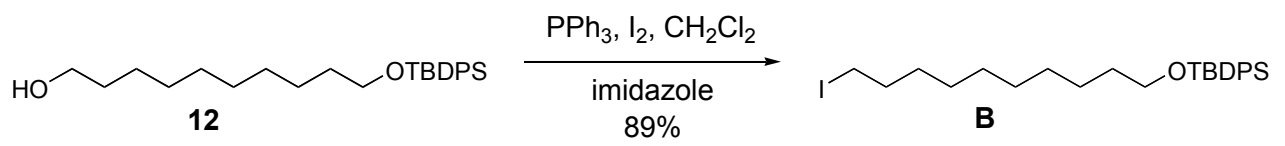

10-(tert-Butyldiphenylsilanyloxy)-1-iododecane (B), To a solution of triphenylphosphine $(1.9 \mathrm{~g}, 7.4 \mathrm{mmol})$ and imidazole $(500 \mathrm{mg}, 7.4 \mathrm{mmol})$ in $\mathrm{CH}_{2} \mathrm{Cl}_{2}(30 \mathrm{~mL})$ was added iodine $(1.9 \mathrm{~g}$, $7.4 \mathrm{mmol}$ ) in small portions over $10 \mathrm{~min}$. After the addition of iodine was complete, the reaction was stirred at ambient temperature for $10 \mathrm{~min}$. The alcohol 12 (2.6 g, $6.2 \mathrm{mmol})$ was then added slowly as a solution in $\mathrm{CH}_{2} \mathrm{Cl}_{2}(30 \mathrm{~mL})$ over $5 \mathrm{~min}$. The reaction mixture was stirred at ambient temperature for $30 \mathrm{~min}$ at which time TLC analysis showed the reaction to be complete. The mixture was diluted with hexanes $(100 \mathrm{~mL})$ and the solids were removed by filtration. The filtrate was concentrated and purified by chromatography $\left(\mathrm{SiO}_{2}, 1 \%\right.$ to $3 \% \mathrm{Et}_{2} \mathrm{O}$-hexanes) to give $2.9 \mathrm{~g}$ (89\%) of B: ${ }^{1} \mathrm{H}$ NMR (400 MHz, $\left.\mathrm{CDCl}_{3}\right) \square 7.65-7.61(\mathrm{~m}, 4 \mathrm{H}), 7.41-7.31(\mathrm{~m}, 6 \mathrm{H}), 3.61(\mathrm{t}, J=6.8$ $\mathrm{Hz}, 2 \mathrm{H}), 3.15$ (t, $J=6.8 \mathrm{~Hz}, 2 \mathrm{H}), 1.78$ (q, J = 7.2 Hz, 2H), 1.55-1.47 (m, 12H), $1.00(\mathrm{~s}, 9 \mathrm{H}) ;{ }^{13} \mathrm{C}$ NMR (100 MHz, $\left.\mathrm{CDCl}_{3}\right) \square 135.8,134.4,129.7,127.8,64.2,33.8,32.8,30.7,29.7,29.6,29.5,28.7$, 27.1, 26.0, 19.4, 7.6; HRMS calcd for $\mathrm{C}_{26} \mathrm{H}_{39} \mathrm{IOSi}, 523.1893 \mathrm{~m} / \mathrm{z}(\mathrm{M}+\mathrm{H})^{+}$; observed $523.1895 \mathrm{~m} / z$. 

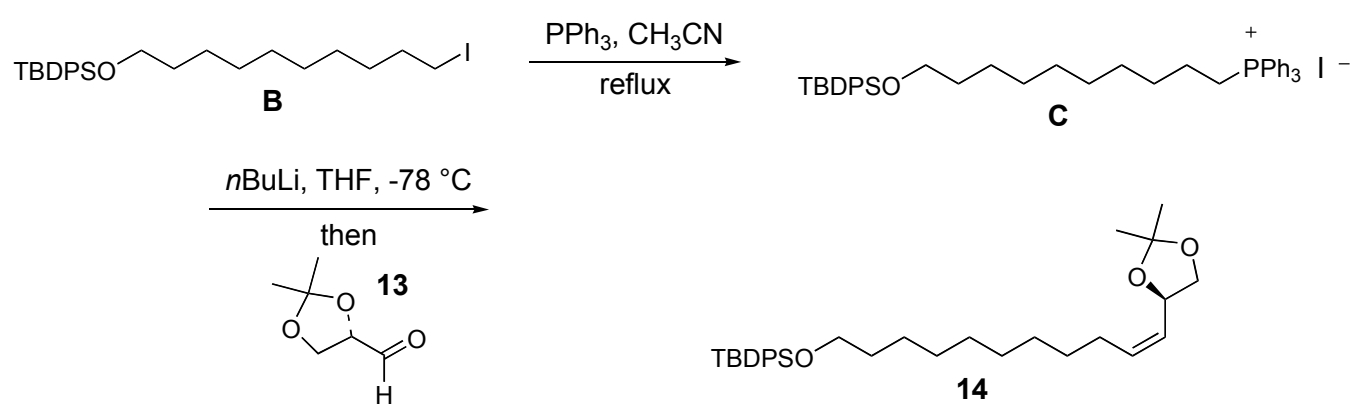

1-(tert-Butyldiphenylsilanyl)-11-[(4R)-2,2-dimethyl-[1,3]dioxolan-4-yl]-undec-10(E)-en1-ol (14): To a solution of iodide $\mathbf{B}(6.7 \mathrm{~g}, 12.8 \mathrm{mmol})$ in $\mathrm{CH}_{3} \mathrm{CN}(13 \mathrm{~mL})$ was added triphenylphosphine ( $3.3 \mathrm{~g}, 12.8 \mathrm{mmol}$ ). The mixture was heated to reflux for $24 \mathrm{~h}$ under $\mathrm{N}_{2}$, cooled to room temperature, and concentrated to a thick oil. The crude phosphonium iodide was used in the next step without purification.

To a solution of the phosphonium iodide $\mathbf{C}(16.9 \mathrm{~g}, 21.5 \mathrm{mmol})$ in THF $(105 \mathrm{~mL})$ at $-78{ }^{\circ} \mathrm{C}$ was added a solution of $n$-BuLi in hexanes $(2.45 \mathrm{M}, 8.6 \mathrm{~mL}, 21.1 \mathrm{mmol})$ slowly over $5 \mathrm{~min}$. The reaction turned bright red upon addition of the $n$-BuLi. A solution of $(S)$-glyceraldehyde acetonide (13) $(5.4 \mathrm{~g}, 41.1 \mathrm{mmol})$ in THF $(10 \mathrm{~mL})$ was added to the ylid solution slowly over $5 \mathrm{~min}$. The reaction was stirred at $-78^{\circ} \mathrm{C}$ for $2 \mathrm{~h}$ and then the bath was removed and the reaction was allowed to warm to ambient temperature. The reaction was quenched with sat. $\mathrm{NH}_{4} \mathrm{Cl}$. The organic layer was separated and the aqueous layer was extracted with hexanes. The combined organics were dried over $\mathrm{MgSO}_{4}$, concentrated, and purified by chromatography $\left(\mathrm{SiO}_{2}, 5 \% \mathrm{Et}_{2} \mathrm{O}\right.$-hexanes) to give $8.9 \mathrm{~g}$ (83\%) of $\mathbf{1 4}$ as a colorless oil: [ []$_{\mathrm{D}}{ }^{23.0}=-2.4\left(\mathrm{c} 1.0, \mathrm{CHCl}_{3}\right) ;{ }^{1} \mathrm{H}$ NMR $\left(500 \mathrm{MHz}, \mathrm{CDCl}_{3}\right) \square 7.68$ $(\mathrm{dd}, J=6.0,2.0 \mathrm{~Hz}, 4 \mathrm{H}), 7.46-7.36(\mathrm{~m}, 6 \mathrm{H}), 5.68-5.61(\mathrm{~m}, 1 \mathrm{H}), 5.44-5.38(\mathrm{~m}, 1 \mathrm{H}), 4.89-4.83(\mathrm{~m}$, $1 \mathrm{H}), 4.07(\mathrm{dd}, J=8.0,6.0 \mathrm{~Hz}, 1 \mathrm{H}), 3.66(\mathrm{t}, J=6.5 \mathrm{~Hz}, 2 \mathrm{H}), 3.52(\mathrm{t}, J=8.0 \mathrm{~Hz}, 1 \mathrm{H}), 2.19-2.02(\mathrm{~m}$, $2 \mathrm{H}), 1.60-1.53(\mathrm{~m}, 2 \mathrm{H}), 1.44(\mathrm{~s}, 3 \mathrm{H}), 1.41(\mathrm{~s}, 3 \mathrm{H}), 1.40-1.23(\mathrm{~m}, 12 \mathrm{H}), 1.06(\mathrm{~s}, 9 \mathrm{H}) ;{ }^{13} \mathrm{C}$ NMR $(125$ $\left.\mathrm{MHz}, \mathrm{CDCl}_{3}\right) \square 135.8,135.5,134.4,129.7,127.8,127.2,109.3,72.3,69.7,64.2,32.8,29.9,29.8$, 29.7, 29.6, 29.4, 28.0, 27.1, 27.1, 26.3, 26.0, 19.5; IR (thin film) 2929, 2856, 1472, 1427, 1369, $1214,1155,1111,1060,860,823,739,701 \mathrm{~cm}^{-1}$; HRMS calcd for $\mathrm{C}_{32} \mathrm{H}_{48} \mathrm{O}_{3} \mathrm{Si}, 531.3270 \mathrm{~m} / \mathrm{z}$ $(\mathrm{M}+\mathrm{Na})^{+}$; observed $531.3260 \mathrm{~m} / \mathrm{z}$. Anal. Calcd for $\mathrm{C}_{32} \mathrm{H}_{48} \mathrm{O}_{3} \mathrm{Si}$; C, 75.54; H, 9.51. Found: C, 75.80; H, 9.63 .

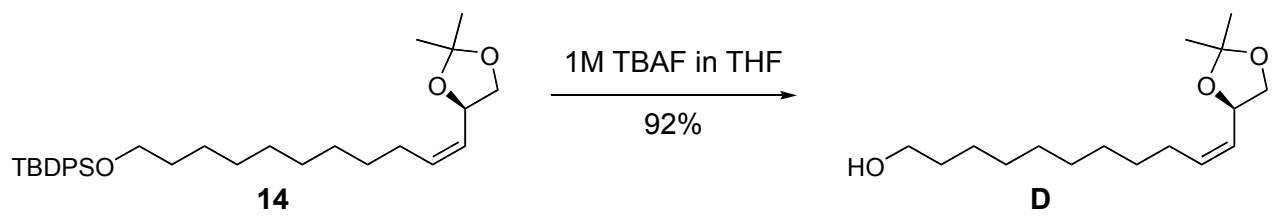

(10E, 4R)-11-(2,2-Dimethyl-[1,3]dioxolan-4-yl)-undec-10-en-1-ol (D): To a solution of $14(8.0 \mathrm{~g}, 15.7 \mathrm{mmol})$ in THF $(50 \mathrm{~mL})$ was added $1 \mathrm{M}$ TBAF in THF $(32 \mathrm{~mL}, 31.5 \mathrm{mmol})$ in one 
portion at ambient temperature. The mixture was stirred for $20 \mathrm{~h}$, then was diluted with hexanes $(100 \mathrm{~mL})$ and washed with $1 \mathrm{M} \mathrm{HCl}(2 \times 50 \mathrm{~mL})$ and saturated $\mathrm{NaHCO}_{3}(1 \times 50 \mathrm{~mL})$. The organic layer was dried over $\mathrm{Na}_{2} \mathrm{SO}_{4}$, concentrated, and the crude product was purified by chromatography $\left(\mathrm{SiO}_{2}, 10 \%\right.$ to $20 \%$ to $25 \%$ EtOAc-hexanes) to give $3.9 \mathrm{~g}(92 \%)$ of $\mathbf{D}$ as a colorless oil: [ $[\mathrm{C}]_{\mathrm{D}}{ }^{23.0}=\mathrm{-}$ 4.9 (c 3.5, $\left.\mathrm{CHCl}_{3}\right)$; ${ }^{1} \mathrm{H}$ NMR $\left(500 \mathrm{MHz}, \mathrm{CDCl}_{3}\right) \square 5.67-5.61$ (m, $\left.1 \mathrm{H}\right), 5.43-5.38(\mathrm{~m}, 1 \mathrm{H}), 4.88-4.83$ (m, 1H), $4.07(\mathrm{dd}, J=8.0,6.0 \mathrm{~Hz}, 1 \mathrm{H}), 3.65(\mathrm{t}, J=7.0 \mathrm{~Hz}, 2 \mathrm{H}), 3.52(\mathrm{t}, J=8.0 \mathrm{~Hz}, 1 \mathrm{H}), 2.28-2.04$ (m, 2H), 1.60-1.54 (m, 2H), $1.44(\mathrm{~s}, 3 \mathrm{H}), 1.41(\mathrm{~s}, 3 \mathrm{H}), 1.40-1.27(\mathrm{~m}, 13 \mathrm{H}) ;{ }^{13} \mathrm{C}$ NMR $(125 \mathrm{MHz}$, $\left.\mathrm{CDCl}_{3}\right) \square 135.4,127.2,109.3,72.2,69.6,63.1,33.0,29.8,29.7,29.6,29.6,29.3,27.9,27.0,26.1$, 26.0; IR (thin film) 3436, 2985, 2926, 2870, 1660, 1456, 1371, 1215, 1156, 1058, 860, 792, $723 \mathrm{~cm}^{-}$ '; HRMS calcd for $\mathrm{C}_{16} \mathrm{H}_{30} \mathrm{O}_{3}, 293.2093 \mathrm{~m} / \mathrm{z}(\mathrm{M}+\mathrm{Na})^{+}$; observed $293.2100 \mathrm{~m} / \mathrm{z}$. Anal. Calcd for $\mathrm{C}_{16} \mathrm{H}_{30} \mathrm{O}_{3} ; \mathrm{C}, 71.07 ; \mathrm{H}, 11.18$. Found: $\mathrm{C}, 70.80 ; \mathrm{H}, 11.39$.

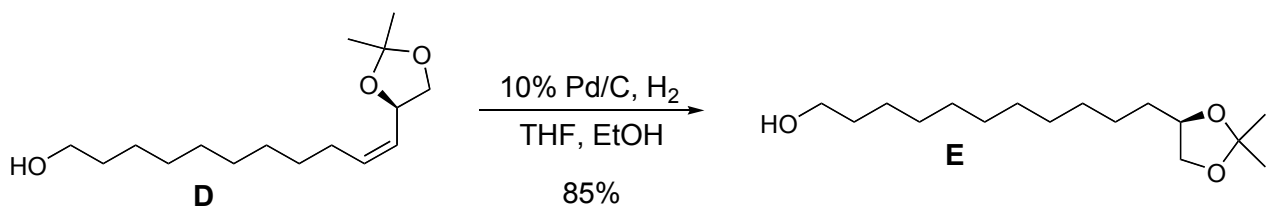

(4R)-11-(2,2-Dimethyl-[1,3]dioxolan-4-yl)-undecan-1-ol (E). To a solution of alcohol D $(4.2 \mathrm{~g}, 15.5 \mathrm{mmol})$ in THF $(75 \mathrm{~mL})$ and $\mathrm{EtOH}(75 \mathrm{~mL})$ was added $10 \% \mathrm{Pd} / \mathrm{C}(600 \mathrm{mg})$. The reaction flask was evacuated and purged with hydrogen three times. The reaction mixture was stirred under a $\mathrm{H}_{2}$ atmosphere at ambient temperature for $2 \mathrm{~h}$. The flask was then evacuated and purged with nitrogen three times and the catalyst was removed by filtration through Celite. The filtrate was concentrated and the crude product purified by chromatography $\left(\mathrm{SiO}_{2}, 10 \%\right.$ to $15 \%$ to $20 \%$ to $25 \%$ EtOAc-hexanes) to give $3.6 \mathrm{~g}(85 \%)$ of alcohol $\mathbf{E}$ as a white solid: $[\square]_{\mathrm{D}}{ }^{23.0}=-12.5$ (c $\left.10.8, \mathrm{CHCl}_{3}\right) ;{ }^{1} \mathrm{H}$ NMR $\left(500 \mathrm{MHz}, \mathrm{CDCl}_{3}\right) \square 4.12-4.02(\mathrm{~m}, 2 \mathrm{H}), 3.65(\mathrm{t}, J=6.5 \mathrm{~Hz}, 2 \mathrm{H}), 3.51(\mathrm{t}, J$ $=7.5 \mathrm{~Hz}, 1 \mathrm{H}), 1.69-1.24(\mathrm{~m}, 21 \mathrm{H}), 1.42(\mathrm{~s}, 3 \mathrm{H}), 1.37(\mathrm{~s}, 3 \mathrm{H}) ;{ }^{13} \mathrm{C}$ NMR $\left(125 \mathrm{MHz}, \mathrm{CDCl}_{3}\right) \square 108.8$, 76.4, 69.8, 63.3, 33.8, 33.0, 29.9, 29.8, 29.8, 29.7, 29.7, 29.7, 27.2, 26.0, 26.0; IR (thin film) 3401, 2985, 2923, 2855, 1458, 1369, 1215, 1159, 1059, $857 \mathrm{~cm}^{-1}$; HRMS calcd for $\mathrm{C}_{16} \mathrm{H}_{32} \mathrm{O}_{3}, 295.2249$ $m / z(\mathrm{M}+\mathrm{Na})^{+}$; observed $295.2253 \mathrm{~m} / z$. Anal. Calcd for $\mathrm{C}_{16} \mathrm{H}_{32} \mathrm{O}_{3} ; \mathrm{C}, 70.54 ; \mathrm{H}, 11.84$. Found: $\mathrm{C}$, $70.33 ; \mathrm{H}, 11.93$.

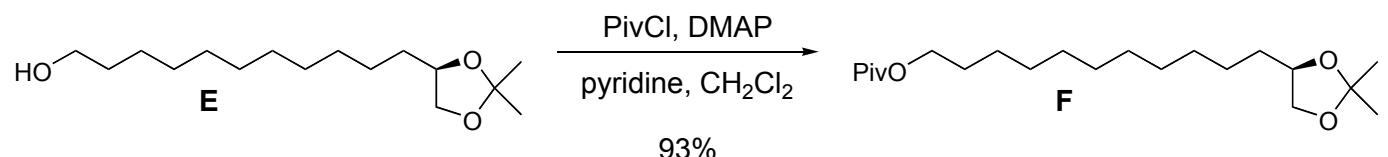

(4R)-2,2-Dimethyl-propionic acid-11-(2,2-dimethyl-[1,3]dioxolan-4-yl)-undecyl ester (F). To a solution of alcohol $\mathbf{E}(1.3 \mathrm{~g}, 4.3 \mathrm{mmol})$, pyridine (1.0 g, $13.0 \mathrm{mmol})$, and DMAP (50 $\mathrm{mg}$, 
$0.4 \mathrm{mmol})$ in $\mathrm{CH}_{2} \mathrm{Cl}_{2}(15 \mathrm{~mL})$ at ambient temperature was added pivaloyl chloride $(1.0 \mathrm{~g}, 8.7$ $\mathrm{mmol}$ ) in one portion. The reaction was stirred at ambient temperature for $20 \mathrm{~h}$ and then quenched with aqueous saturated $\mathrm{NaHCO}_{3}(20 \mathrm{~mL})$. The aqueous layer was extracted with hexanes $(2 \times 30$ $\mathrm{mL}$ ) and the combined organic layers were dried over $\mathrm{MgSO}_{4}$, and concentrated. The crude product was purified by chromatography $\left(\mathrm{SiO}_{2}, 5 \% \mathrm{Et}_{2} \mathrm{O}\right.$-hexanes) to give $1.6 \mathrm{~g}(93 \%)$ of pivaloate $\mathbf{F}$ as a colorless oil: $[\square]_{\mathrm{D}}{ }^{23.0}=-8.9\left(\mathrm{c} 14.2, \mathrm{CHCl}_{3}\right) ;{ }^{1} \mathrm{H}$ NMR $\left(500 \mathrm{MHz}, \mathrm{CDCl}_{3}\right) \square 4.12-4.02$ (m, 4H), 3.51 $(\mathrm{t}, J=7.5 \mathrm{~Hz}, 1 \mathrm{H}), 1.69-1.58(\mathrm{~m}, 3 \mathrm{H}), 1.55-1.45(\mathrm{~m}, 1 \mathrm{H}), 1.42(\mathrm{~s}, 3 \mathrm{H}), 1.37(\mathrm{~s}, 3 \mathrm{H}), 1.36-1.23(\mathrm{~m}$, 16H), $1.21(\mathrm{~s}, 9 \mathrm{H}) ;{ }^{13} \mathrm{C}$ NMR (125 MHz, $\left.\mathrm{CDCl}_{3}\right) \square 178.8,108.7,76.4,69.7,64.6,38.9,33.8,29.9$, 29.7, 29.7, 29.7, 29.4, 28.8, 27.4, 27.3, 27.2, 26.1, 26.0, 26.0; IR (thin film) 2981, 2929, 2856, 1730, $1481,1461,1398,1378,1368,1284,1247,1215,1157,1104,1062$, 979, 939, 859, 792, 771, 722 cm-1; HRMS calcd for $\mathrm{C}_{21} \mathrm{H}_{40} \mathrm{O}_{4}, 379.2824 \mathrm{~m} / z(\mathrm{M}+\mathrm{Na})^{+}$; observed $379.2822 \mathrm{~m} / \mathrm{z}$. Anal. Calcd for $\mathrm{C}_{21} \mathrm{H}_{40} \mathrm{O}_{4} ; \mathrm{C}, 70.74 ; \mathrm{H}, 11.31$. Found: C, 70.81; H, 11.29.

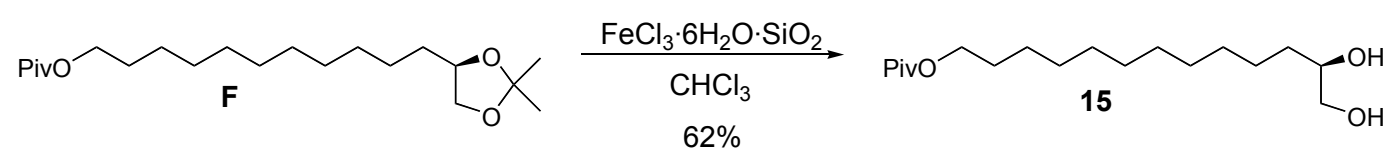

(12R)-2,2-Dimethylpropionic acid-12,13-dihydroxytridecyl ester (15). To a solution of pivaloate $\mathbf{F}(580 \mathrm{mg}, 1.5 \mathrm{mmol})$ in $\mathrm{CHCl}_{3}(10 \mathrm{~mL})$ was added $\mathrm{FeCl}_{3} \cdot 6 \mathrm{H}_{2} \mathrm{O} \cdot \mathrm{SiO}_{2}(1 \mathrm{~g})$ at ambient temperature. The reaction was stirred for $7 \mathrm{~d}$ and then the catalyst was removed by filtration through Celite. The filtrate was concentrated and purified by chromatography $\left(\mathrm{SiO}_{2}, 3 \% \mathrm{MeOH}-\right.$ $\left.\mathrm{CH}_{2} \mathrm{Cl}_{2}\right)$ to give $470 \mathrm{mg}(62 \%)$ of diol 15 as a white solid plus $175 \mathrm{mg}(30 \%)$ of unreacted $\mathbf{F}$ : $[\square]_{\mathrm{D}}{ }^{23.0}=0.4\left(\mathrm{c} 8.2, \mathrm{CHCl}_{3}\right) ;{ }^{1} \mathrm{H} \mathrm{NMR}\left(500 \mathrm{MHz}, \mathrm{CDCl}_{3}\right) \square 4.06(\mathrm{t}, J=6.5 \mathrm{~Hz}, 2 \mathrm{H}), 3.76-3.70(\mathrm{~m}$, $1 \mathrm{H}), 3.68\left(\mathrm{~A}\right.$ of $\left.\mathrm{ABX}, J_{\mathrm{AB}}=11.0 \mathrm{~Hz}, J_{\mathrm{AX}}=3.0 \mathrm{~Hz}, 1 \mathrm{H}\right), 3.45\left(\mathrm{~B}\right.$ of $\mathrm{ABX}, J_{\mathrm{AB}}=11.0 \mathrm{~Hz}, J_{\mathrm{BX}}=8.0$, $1 \mathrm{H}), 1.74(\mathrm{bs}, 2 \mathrm{H}), 1.63$ (q, $J=8.0 \mathrm{~Hz}, 2 \mathrm{H}), 1.48-1.42(\mathrm{~m}, 3 \mathrm{H}), 1.39-1.24(\mathrm{~m}, 15 \mathrm{H}), 1.21(\mathrm{~s}, 9 \mathrm{H})$; ${ }^{13} \mathrm{C}$ NMR (125 MHz, $\left.\mathrm{CDCl}_{3}\right) \square$ 179.0, 72.6, 67.0, 64.7, 39.0, 33.4, 29.9, 29.7, 29.7, 29.7, 29.4, 28.8, 27.4, 26.1, 25.8; IR (thin film) 3369, 2920, 2855, 1731, 1480, 1463, 1398, 1366, 1285, 1158, 1067 , 939, 869, 772, $722 \mathrm{~cm}^{-1}$; HRMS calcd for $\mathrm{C}_{18} \mathrm{H}_{36} \mathrm{O}_{4}, 339.2511 \mathrm{~m} / z(\mathrm{M}+\mathrm{Na})^{+}$; observed 339.2514 $m / z$. Anal. Calcd for $\mathrm{C}_{18} \mathrm{H}_{36} \mathrm{O}_{4} ; \mathrm{C}, 68.31 ; \mathrm{H}, 11.47$. Found: C, 68.01; H, 11.46.

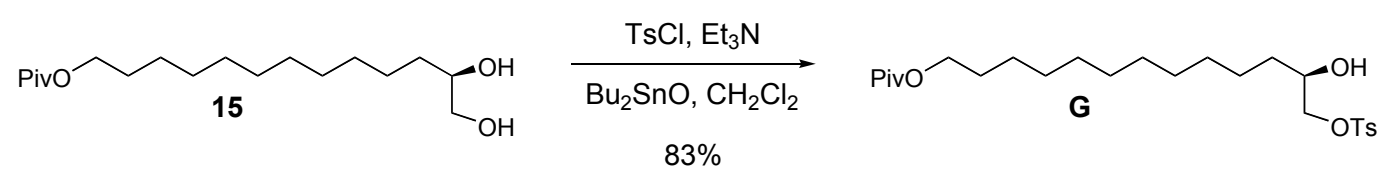

(12R)-2,2-Dimethylpropionic acid-12-hydroxy-13-(toluene-4-sulfonyloxy)-tridecyl ester (G). To a solution of diol $15(520 \mathrm{mg}, 1.7 \mathrm{mmol})$, dibutyltin oxide (8 $\mathrm{mg}, 0.03 \mathrm{mmol})$, and triethylamine $(170 \mathrm{mg}, 1.7 \mathrm{mmol})$ in $\mathrm{CH}_{2} \mathrm{Cl}_{2}(5 \mathrm{~mL})$ was added $p$-toluenesulfonyl chloride $(320 \mathrm{mg}$, 
$1.7 \mathrm{mmol}$ ) as a solid in one portion. The reaction was stirred at ambient temperature for $16 \mathrm{~h}$ and then quenched with aqueous saturated $\mathrm{NaHCO}_{3}(5 \mathrm{~mL})$. The organic layer was dried over $\mathrm{Na}_{2} \mathrm{SO}_{4}$, concentrated, and the crude product purified by chromatography $\left(\mathrm{SiO}_{2}, 20 \%\right.$ EtOAc-hexanes) to give $650 \mathrm{mg}(83 \%)$ of tosylate $\mathbf{G}$ as a white solid: $\left[\mathrm{C}_{\mathrm{D}}{ }^{23.0}=-5.0\left(\mathrm{c} 1.8, \mathrm{CHCl}_{3}\right) ;{ }^{1} \mathrm{H}\right.$ NMR (500 $\left.\mathrm{MHz}, \mathrm{CDCl}_{3}\right) \square 7.82(\mathrm{~d}, J=8.5 \mathrm{~Hz}, 2 \mathrm{H}), 7.37(\mathrm{~d}, J=8.0 \mathrm{~Hz}, 2 \mathrm{H}), 4.07-4.04(\mathrm{~m}, 3 \mathrm{H}), 3.91-3.82(\mathrm{~m}$, $2 \mathrm{H}), 2.47(\mathrm{~s}, 3 \mathrm{H}), 2.02(\mathrm{bs}, 1 \mathrm{H}), 1.62(\mathrm{q}, J=7.5 \mathrm{~Hz}, 2 \mathrm{H}), 1.46-1.23(\mathrm{~m}, 18 \mathrm{H}), 1.21(\mathrm{~s}, 9 \mathrm{H}) ;{ }^{13} \mathrm{C}$ NMR $\left(125 \mathrm{MHz}, \mathrm{CDCl}_{3}\right) \square 178.9,145.3,132.9,130.2,128.2,74.2,69.7,64.7,39.0,32.9,29.7$, 29.7, 29.7, 29.7, 29.4, 28.8, 27.4, 26.1, 25.5, 21.9; IR (thin film) 3504, 2928, 2855, 2360, 1727, $1598,1480,1459,1399,1363,1287,1189,1098,1036,969,814,667 \mathrm{~cm}^{-1}$; HRMS calcd for $\mathrm{C}_{25} \mathrm{H}_{42} \mathrm{O}_{6} \mathrm{~S}, 493.2600 \mathrm{~m} / z(\mathrm{M}+\mathrm{Na})^{+}$; observed $493.2614 \mathrm{~m} / z$. Anal. Calcd for $\mathrm{C}_{25} \mathrm{H}_{42} \mathrm{O}_{6} \mathrm{~S} ; \mathrm{C}, 63.80$; H, 8.99. Found: C, 63.72; H, 8.92 .
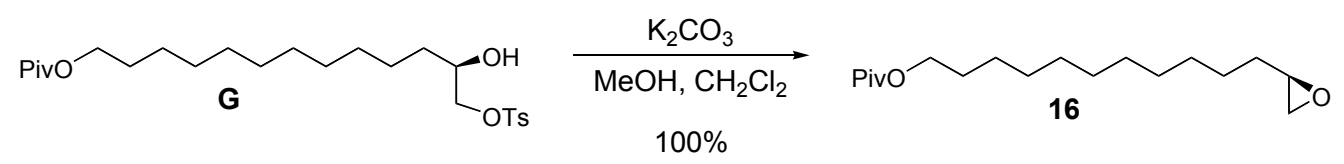

(12R)-2,2-Dimethylpropionic acid-12,13-epoxytridecyl ester (16). To a solution of tosylate $\mathbf{G}(650 \mathrm{mg}, 1.4 \mathrm{mmol})$ in $\mathrm{MeOH}(12 \mathrm{~mL})$ and $\mathrm{CH}_{2} \mathrm{Cl}_{2}(1.2 \mathrm{~mL})$ at $0{ }^{\circ} \mathrm{C}$ was added $\mathrm{K}_{2} \mathrm{CO}_{3}$ (290 mg, $2.1 \mathrm{mmol}$ ) as a solid in one portion. The reaction was stirred at $0{ }^{\circ} \mathrm{C}$ for $1 \mathrm{~h}$ and then quenched with $\mathrm{HCl}(1 \mathrm{M}, 2.5 \mathrm{~mL})$. The organic layer was washed with aqueous saturated $\mathrm{NaHCO}_{3}$ (30 mL), dried over $\mathrm{MgSO}_{4}$, and concentrated to give $410 \mathrm{mg}(100 \%)$ of epoxide 16 as a colorless oil: $[\square]_{\mathrm{D}}{ }^{23.0}=4.4\left(\mathrm{c} 1.9, \mathrm{CHCl}_{3}\right) ;{ }^{1} \mathrm{H}$ NMR $\left(500 \mathrm{MHz}, \mathrm{CDCl}_{3}\right) \square 4.05(\mathrm{t}, J=6.5 \mathrm{~Hz}, 2 \mathrm{H}), 2.94-2.89$ (m, $1 \mathrm{H}), 2.76(\mathrm{t}, J=3.0 \mathrm{~Hz}, 1 \mathrm{H}), 2.47$ (dd, $J=5.0,2.5 \mathrm{~Hz}, 1 \mathrm{H}), 1.66-1.26(\mathrm{~m}, 20 \mathrm{H}), 1.20(\mathrm{~s}, 9 \mathrm{H})$; ${ }^{13} \mathrm{C}$ NMR $\left(125 \mathrm{MHz}, \mathrm{CDCl}_{3}\right) \square 178.8,64.6,52.6,47.3,38.9,32.7,29.7,29.7,29.7,29.6,29.4,28.8$, 27.4, 26.2, 26.1; IR (thin film) 2928, 2855, 1729, 1480, 1460, 1398, 1365, 1284, 1157, 1034, 836, $771 \mathrm{~cm}^{-1}$; HRMS calcd for $\mathrm{C}_{18} \mathrm{H}_{34} \mathrm{O}_{3}, 321.2406 \mathrm{~m} / z(\mathrm{M}+\mathrm{Na})^{+}$; observed $321.2401 \mathrm{~m} / \mathrm{z}$. Anal. Calcd for $\mathrm{C}_{18} \mathrm{H}_{34} \mathrm{O}_{3} ; \mathrm{C}, 72.44 ; \mathrm{H}, 11.48$. Found: $\mathrm{C}, 72.70 ; \mathrm{H}, 11.73$.

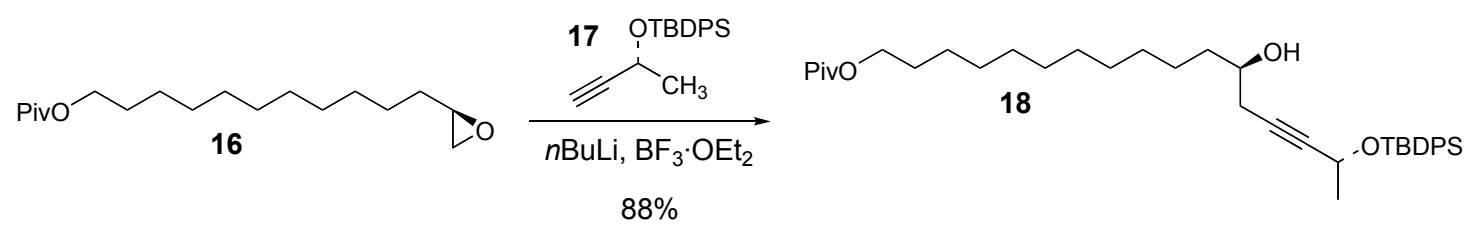

(12R, 16R)-2,2-Dimethylpropionic acid-16-(tert-butyldiphenylsilanyloxy)-12-hydroxyheptadec-14-ynyl ester (18). To a $-78{ }^{\circ} \mathrm{C}$ solution of alkyne $17(840 \mathrm{mg}, 4.6 \mathrm{mmol})$ in THF (9 $\mathrm{mL}$ ) was added $n-\mathrm{BuLi}(2.4 \mathrm{M}$ in hexanes, $1.8 \mathrm{~mL}, 4.3 \mathrm{mmol})$. The reaction was stirred for $30 \mathrm{~min}$ and then $\mathrm{BF}_{3} \cdot \mathrm{OEt}_{2}(610 \mathrm{mg}, 4.3 \mathrm{mmol})$ was added in one portion. The reaction was stirred for 30 min and then epoxide $\mathbf{1 6}(1.0 \mathrm{~g}, 2.3 \mathrm{mmol})$ was added as a solution in THF $(5 \mathrm{~mL})$ slowly over 5 
min. The reaction mixture was stirred at $-78{ }^{\circ} \mathrm{C}$ for $1 \mathrm{~h}$ and then quenched with aqueous saturated $\mathrm{NH}_{4} \mathrm{Cl}(5 \mathrm{~mL})$ and warmed to room temperature. The aqueous layer was washed with $\mathrm{Et}_{2} \mathrm{O}(2 \times 30$ $\mathrm{mL}$ ) and the combined organic layers were dried over $\mathrm{Na}_{2} \mathrm{SO}_{4}$ and concentrated. The crude product was purified by chromatography $\left(\mathrm{SiO}_{2}, 10 \% \mathrm{Et}_{2} \mathrm{O}\right.$-hexanes) to give $1.3 \mathrm{~g}(88 \%)$ of 18 as a colorless oil: $[\square]]_{\mathrm{D}}^{23.0}=55.2\left(\mathrm{c} \mathrm{3.9}, \mathrm{CHCl}_{3}\right) ;{ }^{1} \mathrm{H}$ NMR $\left(500 \mathrm{MHz}, \mathrm{CDCl}_{3}\right) \square 7.78-7.75(\mathrm{~m}, 2 \mathrm{H}), 7.72-7.69(\mathrm{~m}$, $2 \mathrm{H}), 7.46-7.37(\mathrm{~m}, 6 \mathrm{H}), 4.54-4.48(\mathrm{~m}, 1 \mathrm{H}), 4.07(\mathrm{t}, \mathrm{J}=7.0 \mathrm{~Hz}, 2 \mathrm{H}), 3.56-3.50(\mathrm{~m}, 1 \mathrm{H}), 2.30$ (A of $\left.\mathrm{ABXX}, J_{\mathrm{AB}}=16.5 \mathrm{~Hz}, J_{\mathrm{AX}}=4.5 \mathrm{~Hz}, J_{\mathrm{AX}}=2.0 \mathrm{~Hz}, 1 \mathrm{H}\right), 2.17\left(\mathrm{~B}\right.$ of $\mathrm{ABXX}, J_{\mathrm{AB}}=16.5 \mathrm{~Hz}, J_{\mathrm{BX}}=$ $\left.7.0 \mathrm{~Hz}, J_{\mathrm{BX}}=2.0 \mathrm{~Hz}, 1 \mathrm{H}\right), 1.63(\mathrm{q}, \mathrm{J}=7.5 \mathrm{~Hz}, 2 \mathrm{H}), 1.42(\mathrm{~d}, \mathrm{~J}=6.5 \mathrm{~Hz}, 3 \mathrm{H}), 1.43-1.25(\mathrm{~m}, 19 \mathrm{H})$, $1.21(\mathrm{~s}, 9 \mathrm{H}), 1.07$ (s, 9H); ${ }^{13} \mathrm{C} \mathrm{NMR}\left(125 \mathrm{MHz}, \mathrm{CDCl}_{3}\right) \square 178.9,136.2,136.1,136.0,134.2,134.0$, 130.0, 129.9, 127.9, 127.7, 85.4, 80.7, 70.1, 64.7, 60.3, 40.0, 36.4, 29.8, 29.8, 29.8, 29.8, 29.5, 28.9, 27.9, 27.5, 27.1, 26.2, 25.9, 25.7, 19.4; IR (thin film) 3468, 3072, 2930, 2856, 1729, 1463, 1428, 1398, 1368, 1342, 1285, 1160, 1106, 1082, 1027, 955, 823, 740, 702, $613 \mathrm{~cm}^{-1}$; HRMS calcd for $\mathrm{C}_{38} \mathrm{H}_{58} \mathrm{O}_{4} \mathrm{Si}, 629.4002 \mathrm{~m} / z(\mathrm{M}+\mathrm{Na})^{+}$; observed $629.4013 \mathrm{~m} / \mathrm{z}$. Anal. Calcd for $\mathrm{C}_{38} \mathrm{H}_{58} \mathrm{O}_{4} \mathrm{Si} ; \mathrm{C}$, 75.20; H, 9.63. Found: C, 75.13; H, 9.53.

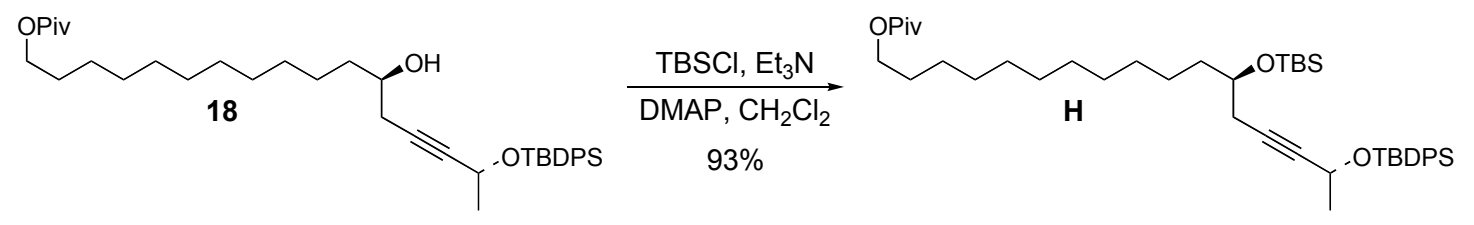

(12R, 16R)-2,2-Dimethylpropionic acid-16-(tert-butyldiphenylsilanyloxy)-12-(tert-butyldimethylsilanyloxy)-heptadec-14-ynyl ester (H). To a solution of alcohol 18 (1.6 g, $2.6 \mathrm{mmol})$, triethylamine (1.1 g, $10.6 \mathrm{mmol})$, and DMAP $(32 \mathrm{mg}, 0.3 \mathrm{mmol})$ in $\mathrm{CH}_{2} \mathrm{Cl}_{2}(10 \mathrm{~mL})$ was added TBSCl $(1.2 \mathrm{~g}, 7.9 \mathrm{mmol})$ as a solid in one portion. The reaction was stirred at ambient temperature for $24 \mathrm{~h}$ and then diluted with hexanes $(20 \mathrm{~mL})$ and $\mathrm{Et}_{2} \mathrm{O}(20 \mathrm{~mL})$. The mixture was washed with $\mathrm{HCl}(1 \mathrm{M}, 2$ X $20 \mathrm{~mL})$, aqueous saturated $\mathrm{NaHCO}_{3}(20 \mathrm{~mL})$, dried over $\mathrm{MgSO}_{4}$, and concentrated. The residue was purified by chromatography $\left(\mathrm{SiO}_{2}, 5 \% \mathrm{Et}_{2} \mathrm{O}\right.$-hexanes) to give $1.8 \mathrm{~g}(93 \%)$ of $\mathbf{H}$ as a colorless oil: $[\square]_{\mathrm{D}}^{23.0}=60.3\left(\mathrm{c} 3.2, \mathrm{CHCl}_{3}\right) ;{ }^{1} \mathrm{H} \mathrm{NMR}\left(500 \mathrm{MHz}, \mathrm{CDCl}_{3}\right) \square 7.78-7.75(\mathrm{~m}, 2 \mathrm{H})$, 7.71-7.68 (m, 2H), 7.45-7.35 (m, 6H), 4.49-4.44 (m, 1H), $4.05(\mathrm{t}, J=7.0 \mathrm{~Hz}, 2 \mathrm{H}), 3.69-3.63(\mathrm{~m}$, $1 \mathrm{H}$ ), 2.25 (A of ABXX', $\left.J_{\mathrm{AB}}=16.5 \mathrm{~Hz}, J_{\mathrm{AX}}=5.0 \mathrm{~Hz}, J_{\mathrm{AX}}=2.0 \mathrm{~Hz}, 1 \mathrm{H}\right), 2.21\left(\mathrm{~B}\right.$ of ABXX', $J_{\mathrm{AB}}=$ $\left.16.5 \mathrm{~Hz}, J_{\mathrm{BX}}=7.5 \mathrm{~Hz}, J_{\mathrm{BX}}=2.0 \mathrm{~Hz}, 1 \mathrm{H}\right), 1.66-1.59(\mathrm{~m}, 2 \mathrm{H}), 1.58-1.50(\mathrm{~m}, 1 \mathrm{H}), 1.36(\mathrm{~d}, J=6.5$ $\mathrm{Hz}, 3 \mathrm{H}), 1.45-1.23(\mathrm{~m}, 17 \mathrm{H}), 1.21(\mathrm{~s}, 9 \mathrm{H}), 1.08(\mathrm{~s}, 9 \mathrm{H}), 0.88(\mathrm{~s}, 9 \mathrm{H}), 0.05(\mathrm{~s}, 6 \mathrm{H}) ;{ }^{13} \mathrm{C}$ NMR $(125$ $\left.\mathrm{MHz}, \mathrm{CDCl}_{3}\right) \square$ 178.9, 136.2, 136.0, 134.3, 134.1, 130.0, 129.9, 129.8, 127.9, 127.8, 127.6, 84.3, 81.6, 71.4, 64.7, 60.4, 39.0, 36.8, 31.9, 29.9, 29.9, 29.9, 29.8, 29.8, 29.5, 28.9, 27.9, 27.5, 27.1, $27.1,26.2,26.1,26.0,25.9,25.7,25.4,22.9,19.5,18.3,14.4,-4.2,-4.4$; IR (thin film) 3072,3050 , 2930, 2857, 1730, 1472, 1463, 1428, 1390, 1362, 1344, 1284, 1256, 1160, 1099, 1027, 1006, 956, $940,836,824,775,739,702,613 \mathrm{~cm}^{-1}$; HRMS calcd for $\mathrm{C}_{44} \mathrm{H}_{72} \mathrm{O}_{4} \mathrm{Si}_{2}, 743.4867 \mathrm{~m} / z(\mathrm{M}+\mathrm{Na})^{+}$; 
observed $743.4874 \mathrm{~m} / z$. Anal. Calcd for $\mathrm{C}_{44} \mathrm{H}_{72} \mathrm{O}_{4} \mathrm{Si}_{2} ; \mathrm{C}, 73.28 ; \mathrm{H}, 10.06$. Found: C, 72.91; $\mathrm{H}$, 10.23 .
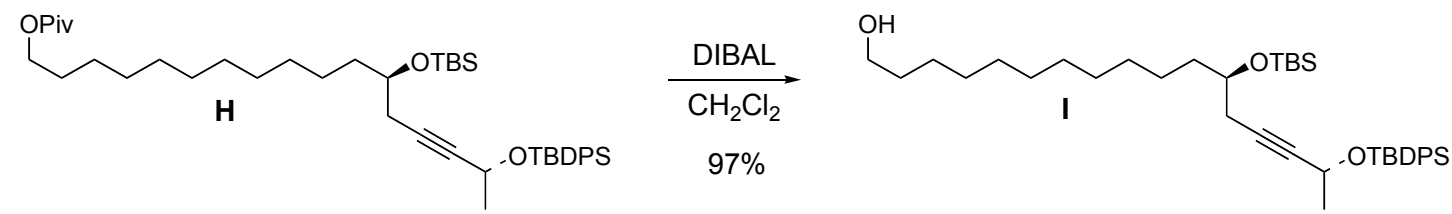

(12 R, 16 R) - 12 - (tert-Butyldimethylsilanyloxy)-16-(tert-butyldiphenylsilanyloxy)heptadec-14-yn-1-ol (I). To a $-78{ }^{\circ} \mathrm{C}$ solution of $\mathbf{H}(220 \mathrm{mg}, 0.3 \mathrm{mmol})$ in $\mathrm{CH}_{2} \mathrm{Cl}_{2}(0.6 \mathrm{~mL})$ at was added diisobutylaluminum hydride ( $1 \mathrm{M}$ in hexanes, $0.9 \mathrm{~mL}, 0.9 \mathrm{mmol})$. The reaction was stirred at $-78{ }^{\circ} \mathrm{C}$ for $30 \mathrm{~min}$ and then quenched with aqueous saturated sodium potassium tartrate $(1 \mathrm{~mL})$ and warmed to ambient temperature. The reaction was diluted with hexanes $(5 \mathrm{~mL})$ and stirred for $3 \mathrm{~h}$. The aqueous layer was washed with hexanes $(5 \mathrm{~mL})$ and the combined organic layers were dried over $\mathrm{Na}_{2} \mathrm{SO}_{4}$, and concentrated. The crude product was purified by chromatography $\left(\mathrm{SiO}_{2}, 15 \%\right.$

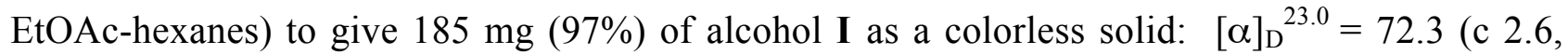
$\left.\mathrm{CHCl}_{3}\right) ;{ }^{1} \mathrm{H} \mathrm{NMR}\left(500 \mathrm{MHz}, \mathrm{CDCl}_{3}\right) \square 7.78-7.75(\mathrm{~m}, 2 \mathrm{H}), 7.71-7.68(\mathrm{~m}, 2 \mathrm{H}), 7.45-7.35(\mathrm{~m}, 6 \mathrm{H})$, 4.50-4.44 (m, 1H), 3.69-3.63 (m, 3H), $2.25\left(\mathrm{~A}_{\text {of }} \mathrm{ABXX}, J_{\mathrm{AB}}=16.5 \mathrm{~Hz}, J_{\mathrm{AX}}=5.0 \mathrm{~Hz}, J_{\mathrm{AX}}=2.0\right.$ $\mathrm{Hz}, 1 \mathrm{H}), 2.21\left(\mathrm{~B}\right.$ of $\left.\mathrm{ABXX}, J_{\mathrm{AB}}=16.5 \mathrm{~Hz}, J_{\mathrm{BX}}=7.5 \mathrm{~Hz}, J_{\mathrm{BX}}=2.0 \mathrm{~Hz}, 1 \mathrm{H}\right), 1.61-1.49(\mathrm{~m}, 5 \mathrm{H})$, $1.37(\mathrm{~d}, J=6.0 \mathrm{~Hz}, 3 \mathrm{H}), 1.45-1.20(\mathrm{~m}, 16 \mathrm{H}), 1.08(\mathrm{~s}, 9 \mathrm{H}), 0.88(\mathrm{~s}, 9 \mathrm{H}), 0.05(\mathrm{~s}, 6 \mathrm{H}) ;{ }^{13} \mathrm{C} \mathrm{NMR}(125$ $\left.\mathrm{MHz}, \mathrm{CDCl}_{3}\right) \square 136.2,136.0,134.3,134.1,129.8,129.8,127.8,127.6,84.3,81.6,71.4,63.3,60.4$, 36.8, 33.1, 29.9, 29.9, 29.9, 29.8, 29.7, 27.9, 27.1, 26.1, 26.0, 25.7, 25.4, 19.4, 18.3, -4.2, -4.4; IR (thin film) 3339, 2930, 2856, 1472, 1428, 1362, 1255, 1161, 1098, 1025, 955, 836, 775, 739, 701 $\mathrm{cm}^{-1}$; HRMS calcd for $\mathrm{C}_{39} \mathrm{H}_{64} \mathrm{O}_{3} \mathrm{Si}_{2}, 659.4292 \mathrm{~m} / z(\mathrm{M}+\mathrm{Na})^{+}$; observed $659.4280 \mathrm{~m} / z$. Anal. Calcd for $\mathrm{C}_{39} \mathrm{H}_{64} \mathrm{O}_{3} \mathrm{Si}_{2} ; \mathrm{C}, 73.52 ; \mathrm{H}, 10.13$. Found: C, 73.59; H, 10.18 .

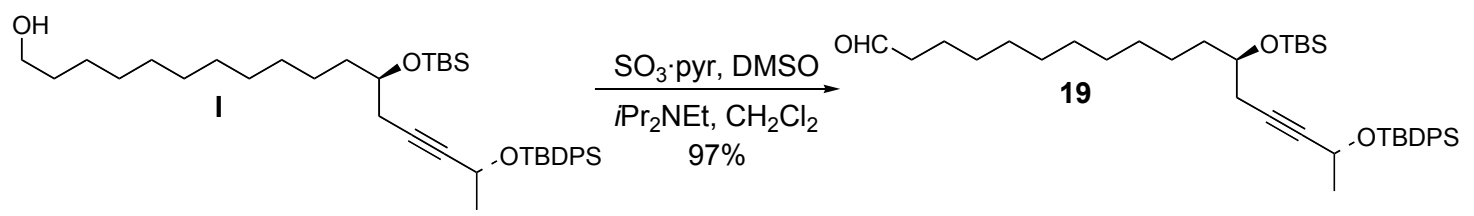

\section{(12 R, 16 R)-12 - (tert-Butyldimethylsilanyloxy)-16-(tert-butyldiphenylsilanyloxy)-} heptadec-14-ynal (19). To a solution of alcohol I (190 mg, $0.3 \mathrm{mmol})$, DMSO (230 mg, 2.9 mmol), and diisopropylethylamine $(190 \mathrm{mg}, 1.5 \mathrm{mmol})$ in $\mathrm{CH}_{2} \mathrm{Cl}_{2}(1.5 \mathrm{~mL})$ at $0{ }^{\circ} \mathrm{C}$ was added $\mathrm{SO}_{3^{-}}$ pyridine complex $(140 \mathrm{mg}, 0.9 \mathrm{mmol})$ as a solid in one portion. The reaction was stirred at $0{ }^{\circ} \mathrm{C}$ for $1 \mathrm{~h}$ and then quenched with aqueous saturated $\mathrm{Na}_{2} \mathrm{~S}_{2} \mathrm{O}_{3}(2 \mathrm{~mL})$ and warmed to room temperature. The aqueous layer was washed with hexanes $(10 \mathrm{~mL})$ and the combined organic layers were dried over $\mathrm{MgSO}_{4}$, and concentrated. The crude product was purified by chromatography $\left(\mathrm{SiO}_{2}, 5 \%\right.$ EtOAc-hexanes) to give $180 \mathrm{mg}(97 \%)$ of aldehyde 19 as a colorless oil: $[\square]_{\mathrm{D}}{ }^{23.0}=63.2$ (c 5.6, 
$\left.\mathrm{CHCl}_{3}\right) ;{ }^{1} \mathrm{H}$ NMR $\left(400 \mathrm{MHz}, \mathrm{CDCl}_{3}\right) \square 9.72(\mathrm{t}, J=2.4 \mathrm{~Hz}, 1 \mathrm{H}), 7.74-7.69(\mathrm{~m}, 2 \mathrm{H}), 7.67-7.62(\mathrm{~m}$, 2H), 7.40-7.29 (m, 6H), 4.46-4.38 (m, 1H), 3.65-3.57 (m, 1H), 2.42 (dt, J=7.0, 1.5 Hz, 2H), 2.26 (A of $\left.\mathrm{ABXX}^{\prime}, J_{\mathrm{AB}}=16.5 \mathrm{~Hz}, J_{\mathrm{AX}}=5.5 \mathrm{~Hz}, J_{\mathrm{AX}}=2.0 \mathrm{~Hz}, 1 \mathrm{H}\right), 2.19\left(\mathrm{~B}^{\prime}\right.$ of $\mathrm{ABXX}, J_{\mathrm{AB}}=16.5 \mathrm{~Hz}$, $\left.J_{\mathrm{BX}}=7.5 \mathrm{~Hz}, J_{\mathrm{BX}}=2.0 \mathrm{~Hz}, 1 \mathrm{H}\right), 1.62-1.44(\mathrm{~m}, 4 \mathrm{H}), 1.31(\mathrm{~d}, J=8.5 \mathrm{~Hz}, 3 \mathrm{H}), 1.42-1.14(\mathrm{~m}, 14 \mathrm{H})$, 1.02 (s, 9H), 0.83 (s, 9H), -0.01 (s, 6H); $\left.{ }^{13} \mathrm{C} \mathrm{NMR} \mathrm{(125} \mathrm{MHz,} \mathrm{CDCl}_{3}\right) \square 203.1,136.2,136.0,134.3$, 134.1, 129.9, 129.8, 127.8, 127.7, 84.3, 81.6, 71.4, 60.4, 44.2, 36.8, 29.9, 29.9, 29.8, 29.7, 29.6, 29.4, 27.9, 27.1, 26.1, 25.7, 25.4, 22.3, 19.5, 18.3, -4.2, -4.4; IR (thin film) 2930, 2856, 1728, 1472 , 1463, 1428, 1390, 1362, 1255, 1161, 1098, 1025, 1006, 955, 836, 775, 739, 702, $612 \mathrm{~cm}^{-1}$; HRMS calcd for $\mathrm{C}_{39} \mathrm{H}_{62} \mathrm{O}_{3} \mathrm{Si}_{2}, 657.4135 \mathrm{~m} / z(\mathrm{M}+\mathrm{Na})^{+}$; observed $657.4125 \mathrm{~m} / z$. Anal. Calcd for $\mathrm{C}_{39} \mathrm{H}_{62} \mathrm{O}_{3} \mathrm{Si}_{2} ; \mathrm{C}, 73.76 ; \mathrm{H}, 9.84$. Found: C, 73.81; H, 10.00 .

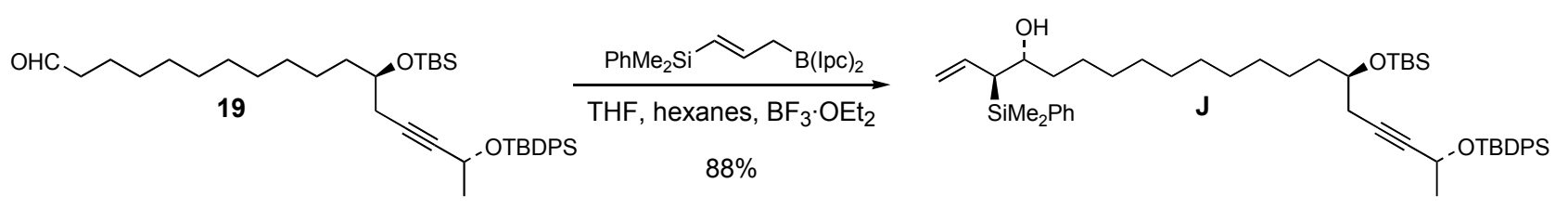

(3S，4R，15R，19R)-15-(tert-Butyld imethylsilanyloxy)-19-(tert-butyldiphenylsilanyloxy)-3-(dimethyl-phenyl-silanyl)-eicos-1-en-17-yn-4-ol (J). To a $-78{ }^{\circ} \mathrm{C}$ solution of $\mathrm{KO} t \mathrm{Bu}(105 \mathrm{mg}, 0.9 \mathrm{mmol})$ in THF (4 mL) was added allyldimethylphenylsilane (180 mg, 1.0 mmol). The mixture was stirred for $5 \mathrm{~min}$, then $n \mathrm{BuLi}(2.6 \mathrm{M}$ in hexanes, $0.33 \mathrm{~mL}, 0.9 \mathrm{mmol})$ was added slowly via syringe over $5 \mathrm{~min}$. The reaction was stirred at $-78{ }^{\circ} \mathrm{C}$ for $10 \mathrm{~min}$ and then warmed to $-45^{\circ} \mathrm{C}$ and stirred for $2 \mathrm{~h}$. The mixture was cooled to $-78{ }^{\circ} \mathrm{C}$ and $(-)-\mathrm{Ipc}_{2} \mathrm{BOMe}(300 \mathrm{mg}$, $0.9 \mathrm{mmol}$ ) was added as a solution in THF $(4 \mathrm{~mL})$ slowly over $5 \mathrm{~min}$. The reaction was stirred for $30 \mathrm{~min}$ and then $\mathrm{BF}_{3} \cdot \mathrm{OEt}_{2}(180 \mathrm{mg}, 1.3 \mathrm{mmol})$ was added in one portion. Five minutes later, a solution of aldehyde 19 (300 mg, $0.5 \mathrm{mmol})$ in hexanes (4 mL) was added slowly over $5 \mathrm{~min}$. The reaction mixture was stirred at $-78{ }^{\circ} \mathrm{C}$ for $4 \mathrm{~h}$ and then quenched with $\mathrm{KOH} / \mathrm{KH}_{2} \mathrm{PO}_{4}$ buffer $(1 \mathrm{M}, 5$ $\mathrm{mL})$ and warmed to room temperature. $\mathrm{H}_{2} \mathrm{O}_{2}(35 \%, 1 \mathrm{~mL})$ was added and the reaction was stirred at ambient temperature for $16 \mathrm{~h}$. The mixture was partitioned between $\mathrm{H}_{2} \mathrm{O}$ and 1:1 hexanes-Et ${ }_{2} \mathrm{O}$. The organic layer was dried over $\mathrm{Na}_{2} \mathrm{SO}_{4}$, concentrated, and purified by chromatography $\left(\mathrm{SiO}_{2}, 5 \%\right.$ $\mathrm{Et}_{2} \mathrm{O}$-hexanes) to give $340 \mathrm{~g}(88 \%)$ of allylsilane $\mathbf{J}$ as a colorless oil : [ $]_{\mathrm{D}}{ }^{23.0}=55.6\left(\mathrm{c}, 1.2, \mathrm{CHCl}_{3}\right)$; ${ }^{1} \mathrm{H}$ NMR $\left(500 \mathrm{MHz}, \mathrm{CDCl}_{3}\right) \square 7.76(\mathrm{dt}, J=6.5,1.5 \mathrm{~Hz}, 2 \mathrm{H}), 7.70(\mathrm{dt}, J=6.5,1.5 \mathrm{~Hz}, 2 \mathrm{H}), 7.57-$ $7.53(\mathrm{~m}, 2 \mathrm{H}), 7.45-7.40(\mathrm{~m}, 2 \mathrm{H}), 7.35-7.40(\mathrm{~m}, 7 \mathrm{H}), 5.84(\mathrm{dt}, J=17.0,10.5 \mathrm{~Hz}, 1 \mathrm{H}), 5.06(\mathrm{dd}, J=$ 10.5, 2.0 Hz, 1H), 4.92 (ddd, $J=17.5,2.0,0.5 \mathrm{~Hz}, 1 \mathrm{H}), 4.50-4.44(\mathrm{~m}, 1 \mathrm{H}), 3.76-3.70$ (m, 1H), 3.69$3.63(\mathrm{~m}, 1 \mathrm{H}), 2.26$ (A of ABXX', $\left.J_{\mathrm{AB}}=16.5 \mathrm{~Hz}, J_{\mathrm{AX}}=5.0 \mathrm{~Hz}, J_{\mathrm{AX}}=1.5 \mathrm{~Hz}, 1 \mathrm{H}\right), 2.20(\mathrm{~B}$ of $\left.\mathrm{ABXX}, J_{\mathrm{AB}}=16.5 \mathrm{~Hz}, J_{\mathrm{BX}}=7.5 \mathrm{~Hz}, J_{\mathrm{BX}}=2.0 \mathrm{~Hz}, 1 \mathrm{H}\right), 1.92(\mathrm{dd}, J=10.5,5.0 \mathrm{~Hz}, 1 \mathrm{H}), 1.59-1.49$ $(\mathrm{m}, 2 \mathrm{H}), 1.45-1.30(\mathrm{~m}, 8 \mathrm{H}), 1.30-1.15(\mathrm{~m}, 14 \mathrm{H}), 1.08(\mathrm{~s}, 9 \mathrm{H}), 0.88(\mathrm{~s}, 9 \mathrm{H}), 0.37(\mathrm{~s}, 3 \mathrm{H}), 0.34(\mathrm{~s}$, $3 \mathrm{H}), 0.05(\mathrm{~s}, 6 \mathrm{H}) ;{ }^{13} \mathrm{C}$ NMR $\left(125 \mathrm{MHz}, \mathrm{CDCl}_{3}\right) \square 138.3,136.2,136.0,135.4,134.3,134.1,129.8$, 
$129.7,129.3,128.0,127.8,127.6,115.7,84.3,81.6,71.7,71.4,67.2,60.4,42.3,37.4,36.6,30.0$, 29.9, 29.9, 29.8, 29.8, 29.8, 28.4, 27.9, 27.1, 26.1, 26.0, 25.7, 25.4, 19.5, 19.4, 18.3, -3.1, -3.7, -4.2, -4.4; IR (thin film) 2929, 2856, 1472, 1428, 1362, 1251, 1161, 1111, 1025, 955, 835, 775, 737, 700 $\mathrm{cm}^{-1}$; HRMS calcd for $\mathrm{C}_{50} \mathrm{H}_{78} \mathrm{O}_{3} \mathrm{Si}_{3}, 833.5157 \mathrm{~m} / z(\mathrm{M}+\mathrm{Na})^{+}$; observed $833.5178 \mathrm{~m} / z$. Anal. Calcd for $\mathrm{C}_{50} \mathrm{H}_{78} \mathrm{O}_{3} \mathrm{Si}_{3} ; \mathrm{C}, 74.01 ; \mathrm{H}, 9.69$. Found: C, 73.84; H, 9.68.

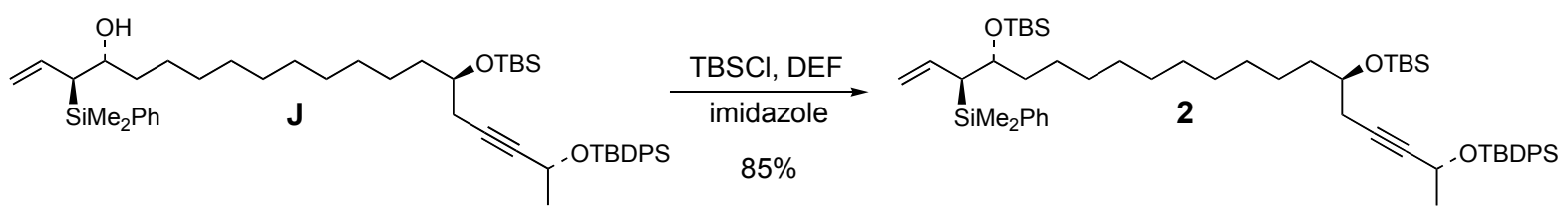

(3S，4R，15R，19R)-4,15-bis-(tert-Butyldimethylsilanyloxy)-19-(tert-butyldiphenylsilanyloxy)-3-(dimethyl-phenyl-silanyl)-eicos-1-en-17-yne (2). To a solution of allylsilane J (190 $\mathrm{mg}, 0.2 \mathrm{mmol}$ ) in diethyl formamide (DEF, $1.0 \mathrm{~mL})$ was added TBSCl $(70 \mathrm{mg}, 0.5 \mathrm{mmol})$ and imidazole (50 mg, $0.7 \mathrm{mmol}$ ). The reaction flask was flushed with nitrogen, sealed with a septum, and heated to $40{ }^{\circ} \mathrm{C}$ for $48 \mathrm{~h}$. TLC analysis showed some remaining starting material and so an additional TBSCl (70 $\mathrm{mg}, 0.5 \mathrm{mmol})$ and imidazole $(50 \mathrm{mg}, 0.7 \mathrm{mmol}$ ) were added to the reaction mixture. After being heated for an additional $24 \mathrm{~h}$, the mixture was partitioned between $\mathrm{H}_{2} \mathrm{O}$ and hexanes. The organic layer was dried over $\mathrm{MgSO}_{4}$, concentrated, and purified by chromatography

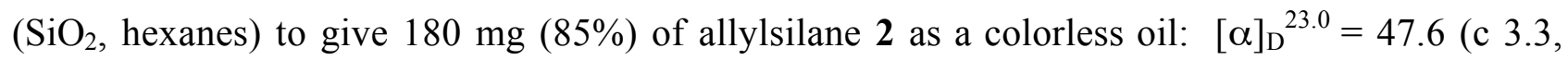
$\left.\mathrm{CHCl}_{3}\right) ;{ }^{1} \mathrm{H} \mathrm{NMR}\left(500 \mathrm{MHz}, \mathrm{CDCl}_{3}\right) \square 7.78-7.75(\mathrm{~m}, 2 \mathrm{H}), 7.71-7.68(\mathrm{~m}, 2 \mathrm{H}), 7.53-7.49$ (m, 2H), 7.45-7.32 (m, 9H), $5.85(\mathrm{dt}, J=17.0,10.5 \mathrm{~Hz}, 1 \mathrm{H}), 4.95(\mathrm{dd}, J=10.5,2.5 \mathrm{~Hz}, 1 \mathrm{H}), 4.74(\mathrm{dd}, J=$ 17.0, $2.0 \mathrm{~Hz}, 1 \mathrm{H}), 4.50-4.44(\mathrm{~m}, 1 \mathrm{H}), 3.86-3.81(\mathrm{~m}, 1 \mathrm{H}), 3.69-3.63(\mathrm{~m}, 1 \mathrm{H}), 2.65$ (A of ABXX', $J_{\mathrm{AB}}$ $\left.=16.5 \mathrm{~Hz}, J_{\mathrm{AX}}=5.0 \mathrm{~Hz}, J_{\mathrm{AX}}=1.5 \mathrm{~Hz}, 1 \mathrm{H}\right), 2.19\left(\mathrm{~B}_{\text {of }} \mathrm{ABXX}, J_{\mathrm{AB}}=16.5 \mathrm{~Hz}, J_{\mathrm{BX}}=7.5 \mathrm{~Hz}, J_{\mathrm{BX}}{ }^{\prime}=\right.$ $2.0 \mathrm{~Hz}, 1 \mathrm{H}), 2.02(\mathrm{dd}, J=10.5,3.5 \mathrm{~Hz}, 1 \mathrm{H}), 1.58-1.47(\mathrm{~m}, 2 \mathrm{H}), 1.37(\mathrm{~d}, J=6.0 \mathrm{~Hz}, 3 \mathrm{H}), 1.45-1.30$ $(\mathrm{m}, 2 \mathrm{H}), 1.30-1.11(\mathrm{~m}, 16 \mathrm{H}), 1.08(\mathrm{~s}, 9 \mathrm{H}), 0.88(\mathrm{~s}, 18 \mathrm{H}), 0.35(\mathrm{~s}, 3 \mathrm{H}), 0.31(\mathrm{~s}, 3 \mathrm{H}), 0.05(\mathrm{~s}, 6 \mathrm{H})$, $0.01(\mathrm{~s}, 3 \mathrm{H}), 0.00(\mathrm{~s}, 3 \mathrm{H}) ;{ }^{13} \mathrm{C} \mathrm{NMR}\left(125 \mathrm{MHz}, \mathrm{CDCl}_{3}\right) \square$ 139.1, 136.3, 136.3, 136.1, 134.4, 134.3, $134.1,129.9,129.8,129.0,127.8,127.8,127.7,114.7,84.3,81.7,73.7,71.5,60.5,40.9,37.2,36.9$, $30.0,30.0,29.9,29.9,28.0,27.2,26.5,26.3,26.2,25.8,25.8,25.5,19.5,18.5,18.4,-2.7,-3.3,-3.4$, $-3.5,-4.1,-4.3$; IR (thin film) 3071, 3050, 2929, 2856, 1472, 1463, 1428, 1390, 1362, 1344, 1254, 1161, 1112, 1083, 1026, 1006, 955, 939, 898, 835, 774, 737, 701, 656, $613 \mathrm{~cm}^{-1}$; HRMS calcd for $\mathrm{C}_{56} \mathrm{H}_{92} \mathrm{O}_{3} \mathrm{Si}_{4}, 947.6021 \mathrm{~m} / z(\mathrm{M}+\mathrm{Na})^{+}$; observed $947.6016 \mathrm{~m} / z$. Anal. Calcd for $\mathrm{C}_{56} \mathrm{H}_{92} \mathrm{O}_{3} \mathrm{Si}_{4}$; $\mathrm{C}$, 72.66; H, 10.02. Found: C, 72.86; H, 10.15. 


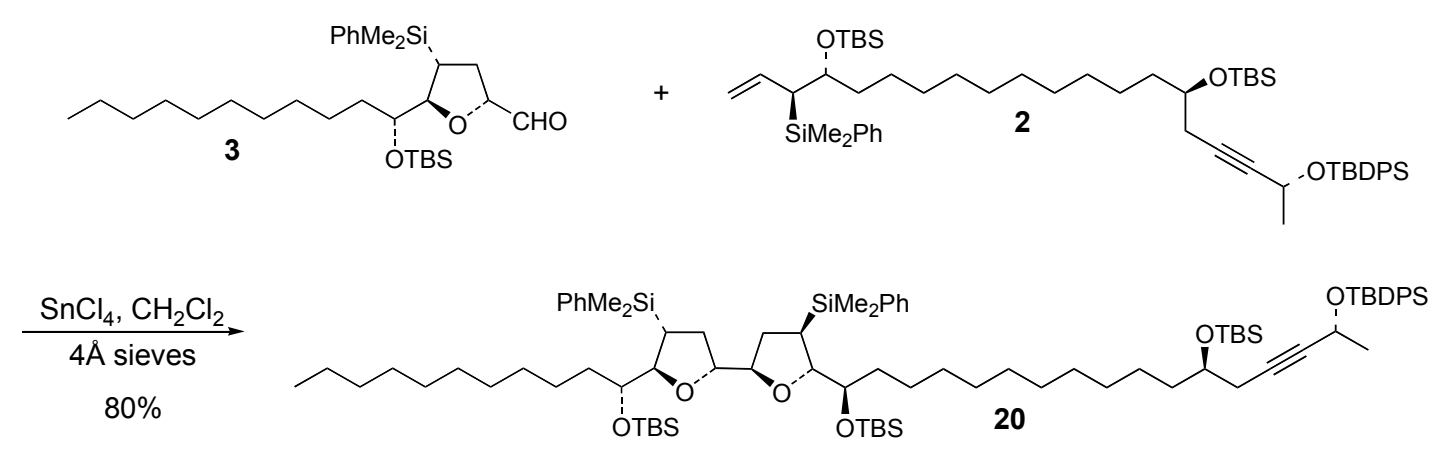

(2R, 2'R, 4R, 4'R, 5S, 5'S)-4,4'-bis-(Dimethylphenylsilanyl)-5-[(1R)-1-(tert-butyldimethylsilanyloxy)-undecyl]-5'-[(1R, 12R, 16R)-1,12-bis-(tert-butyldimethyl-ilanyloxy)-16(tert-butyldiphenylsilanyloxy)-heptadec-14-yne]-octahydro-2,2'-bifuran (20). To a solution of aldehyde 3 (74 mg, $0.14 \mathrm{mmol}$ ), allylsilane 2 (66 mg, $0.07 \mathrm{mmol})$, and flame-dried $4 \AA$ powdered molecular sieves $(50 \mathrm{mg})$ in $\mathrm{CH}_{2} \mathrm{Cl}_{2}(0.35 \mathrm{~mL})$ at $0{ }^{\circ} \mathrm{C}$ was added $\mathrm{SnCl}_{4}(19 \mathrm{mg}, 0.07 \mathrm{mmol})$ dropwise from a syringe. The reaction mixture was stirred at $0{ }^{\circ} \mathrm{C}$ for $4 \mathrm{~h}$ and then quenched with triethylamine $(0.5 \mathrm{~mL})$ and warmed to room temperature. The mixture was diluted with hexanes (1 $\mathrm{mL}), \mathrm{Et}_{2} \mathrm{O}(1 \mathrm{~mL})$, and aqueous saturated $\mathrm{NaHCO}_{3}(1 \mathrm{~mL})$ and stirred for $20 \mathrm{~h}$. The organic layer was dried over $\mathrm{MgSO}_{4}$ and concentrated. Chromatographic purification of the crude product $\left(\mathrm{SiO}_{2}\right.$, $5 \% \mathrm{Et}_{2} \mathrm{O}$-hexanes) then gave $82 \mathrm{mg}(80 \%)$ of $\mathbf{2 0}$ as a colorless oil: [ $]_{\mathrm{D}}{ }^{23.0}=26.8\left(\mathrm{c} 0.2, \mathrm{CHCl}_{3}\right)$; ${ }^{1} \mathrm{H}$ NMR $\left(500 \mathrm{MHz}, \mathrm{CDCl}_{3}\right) \square 7.76(\mathrm{dt}, J=6.5,1.5 \mathrm{~Hz}, 2 \mathrm{H}), 7.70(\mathrm{dt}, J=6.5,1.5 \mathrm{~Hz}, 2 \mathrm{H}), 7.51-$ 7.47 (m, 4H), 7.45-7.32 (m, 12H), 4.50-4.44 (m, 1H), 3.89 (dd, $J=8.5,2.5 \mathrm{~Hz}, 2 \mathrm{H}), 3.77-3.70$ (m, $2 \mathrm{H}), 3.69-3.63(\mathrm{~m}, 1 \mathrm{H}), 3.36-3.30(\mathrm{~m}, 2 \mathrm{H}), 2.26\left(\mathrm{~A}\right.$ of $\mathrm{ABXX}{ }^{\prime}, J_{\mathrm{AB}}=16.0 \mathrm{~Hz}, J_{\mathrm{AX}}=5.0 \mathrm{~Hz}, J_{\mathrm{AX}}{ }^{\prime}=$ $1.5 \mathrm{~Hz}, 1 \mathrm{H}), 2.20\left(\mathrm{~B}\right.$ of $\left.\mathrm{ABXX}, J_{\mathrm{AB}}=16.0 \mathrm{~Hz}, J_{\mathrm{BX}}=7.0 \mathrm{~Hz}, J_{\mathrm{BX}}=2.0 \mathrm{~Hz}, 1 \mathrm{H}\right), 1.88-1.81(\mathrm{~m}$, $2 \mathrm{H}), 1.67-1.50(\mathrm{~m}, 3 \mathrm{H}), 1.38(\mathrm{~d}, J=6.5 \mathrm{~Hz}, 3 \mathrm{H}), 1.45-1.12(\mathrm{~m}, 42 \mathrm{H}), 1.08(\mathrm{~s}, 9 \mathrm{H}), 0.88(\mathrm{~s}, 27 \mathrm{H})$, $0.31(\mathrm{~s}, 6 \mathrm{H}), 0.30(\mathrm{~s}, 6 \mathrm{H}), 0.05(\mathrm{~s}, 6 \mathrm{H}), 0.02(\mathrm{~s}, 6 \mathrm{H}), 0.01(\mathrm{~s}, 6 \mathrm{H}) ;{ }^{13} \mathrm{C} \mathrm{NMR}\left(125 \mathrm{MHz}, \mathrm{CDCl}_{3}\right) \square$ 138.6, 136.2, 136.0, 134.3, 134.1, 134.1, 129.8, 129.8, 129.3, 128.0, 127.8, 127.6, 84.3, 83.4, 83.4, 81.6, 81.4, 74.9, 71.4, 60.4, 36.9, 34.5, 32.4, 32.2, 30.2, 30.1, 30.0, 30.0, 30.0, 30.0, 29.9, 29.9, 29.6, 27.9, 27.1, 26.4, 26.4, 26.3, 26.3, 26.1, 26.0, 25.7, 25.5, 23.0, 19.5, 18.5, 18.3, 14.4, -3.4, -3.4, $-3.8,-4.0,-4.0,-4.2,-4.4,-4.4$; IR (thin film) 2925, 2856, 1472, 1428, 1361, 1251, 1111, 938, 835, 774, 735, $700 \mathrm{~cm}^{-1}$; HRMS calcd for $\mathrm{C}_{86} \mathrm{H}_{146} \mathrm{O}_{6} \mathrm{Si}_{6}, 1465.9633 \mathrm{~m} / z(\mathrm{M}+\mathrm{Na})^{+}$; observed 1465.9636 m/z. Anal. Calcd for $\mathrm{C}_{86} \mathrm{H}_{146} \mathrm{O}_{6} \mathrm{Si}_{6} ; \mathrm{C}, 71.50 ; \mathrm{H}, 10.19$. Found: C, 71.45; H, 10.26.

If the [3+2]-annulation was performed at temperatures below $0{ }^{\circ} \mathrm{C}$, significant amounts of the allylation product $\mathbf{K}$ were obtained (especially at $-40{ }^{\circ} \mathrm{C}$ or $-78{ }^{\circ} \mathrm{C}$ ).

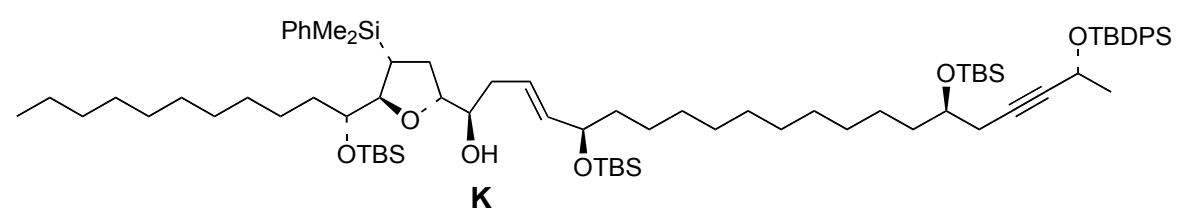




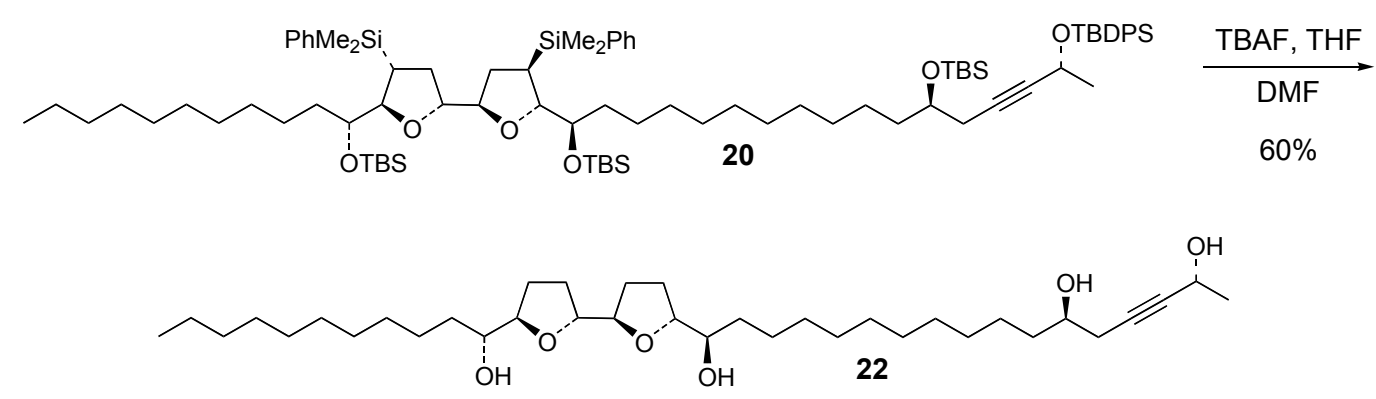

(2R, 2'R, 5R, 5'R)-5-[(1R)-1-hydroxyundecyl]-5'-[(1R, 12R, 16R)-1,12,16-trihydroxyheptadec-14-yne]-octahydro-2,2'-bifuran (22). To a solution of bifuran 20 (44 mg, $0.045 \mathrm{mmol}$ ) in DMF $(0.45 \mathrm{~mL})$ was added TBAF $(1 \mathrm{M}$ in THF, $0.45 \mathrm{~mL}, 0.45 \mathrm{mmol})$. The reaction mixture was then heated to $90{ }^{\circ} \mathrm{C}$ for $6 \mathrm{~h}$. The reaction was cooled to ambient temperature, diluted with hexanes $(10 \mathrm{~mL})$, washed with $\mathrm{HCl}(1 \mathrm{M}, 2 \times 10 \mathrm{~mL})$, and aqueous saturated $\mathrm{NaHCO}_{3}(10 \mathrm{~mL})$. The organic layer was dried over $\mathrm{Na}_{2} \mathrm{SO}_{4}$ and concentrated. The crude product was purified by chromatography $\left(\mathrm{SiO}_{2}, 1 \%\right.$ to $2 \%$ to $\left.3 \% \mathrm{MeOH} / \mathrm{CH}_{2} \mathrm{Cl}_{2}\right)$ to give $13 \mathrm{mg}(60 \%)$ of the tetraol 22 as a white solid: $[\square]]_{\mathrm{D}}^{23.0}=17.0$ (c $\left.0.6, \mathrm{CHCl}_{3}\right) ; 1 \mathrm{H} \mathrm{NMR}\left(500 \mathrm{MHz}, \mathrm{CDCl}_{3}\right)$ d 4.54 (tq, $J=6.5,2.0 \mathrm{~Hz}$, $1 \mathrm{H}), 3.92-3.82(\mathrm{~m}, 4 \mathrm{H}), 3.77-3.71(\mathrm{~m}, 1 \mathrm{H}), 3.41-3.37(\mathrm{~m}, 2 \mathrm{H}), 2.72-2.28(\mathrm{bs}, 4 \mathrm{H}), 2.46$ (A of $\left.\mathrm{ABXX}, J_{\mathrm{AB}}=16.5 \mathrm{~Hz}, J_{\mathrm{AX}}=4.5 \mathrm{~Hz}, J_{\mathrm{AX}}=2.0 \mathrm{~Hz}, 1 \mathrm{H}\right), 2.33\left(\mathrm{~B}\right.$ of $\mathrm{ABXX}, J_{\mathrm{AB}}=16.5 \mathrm{~Hz}, J_{\mathrm{BX}}=$ $\left.6.5 \mathrm{~Hz}, J_{\mathrm{BX}}{ }^{\prime}=2.0 \mathrm{~Hz}, 1 \mathrm{H}\right), 2.02-1.92(\mathrm{~m}, 4 \mathrm{H}), 1.72-1.60(\mathrm{~m}, 4 \mathrm{H}), 1.56-1.23(\mathrm{~m}, 41 \mathrm{H}), 0.89(\mathrm{t}, J=$ $7.0 \mathrm{~Hz}, 3 \mathrm{H}) ;{ }^{13} \mathrm{C}$ NMR $\left(125 \mathrm{MHz}, \mathrm{CDCl}_{3}\right) \square 85.1,83.5,83.4,82.1,82.1,81.1,74.3,70.1,58.6$, $36.4,33.7,33.7,32.2,30.0,29.9,29.9,29.9,29.7,29.6,29.5,29.5,29.5,29.4,29.3,28.6,27.9$, 25.9, 25.7, 25.7, 24.9, 22.9, 14.4; IR (thin film) 3435, 2915, 2850, 1466, 1316, 1069, 959, $860 \mathrm{~cm}^{-1}$; HRMS calcd for $\mathrm{C}_{36} \mathrm{H}_{66} \mathrm{O}_{6}, 617.4757 \mathrm{~m} / z(\mathrm{M}+\mathrm{Na})^{+}$; observed $617.4760 \mathrm{~m} / \mathrm{z}$.

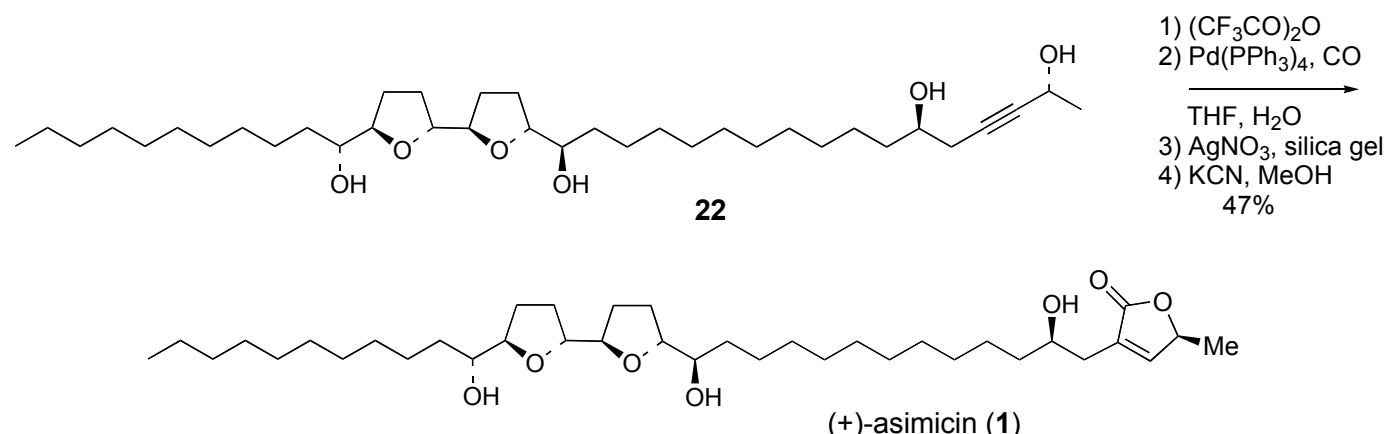

(+)-Asimicin (1): Compound $22(10 \mathrm{mg}, 0.0168 \mathrm{mmol})$ was dissolved in trifluoroacetic anhydride $(0.5 \mathrm{ml})$ and stirred at ambient temperature under a nitrogen atmosphere for 30 minutes. The reaction was concentrated at reduced pressure and dried on a vacuum pump for 1 hour. The residue was dissolved in THF $(0.25 \mathrm{ml})$ and water $(0.02 \mathrm{ml})$ at ambient temperature under a CO atmosphere. $\mathrm{Pd}\left(\mathrm{PPh}_{3}\right)_{4}(0.4 \mathrm{mg}, 0.00034 \mathrm{mmol})$ was added as a solution in THF $(0.02 \mathrm{ml})$ and the 
reaction was stirred for 2 hours. The reaction was diluted with $\mathrm{Et}_{2} \mathrm{O}(5 \mathrm{ml})$ and dried over $\mathrm{MgSO}_{4}$, then concentrated. The residue was dissolved in hexanes $(0.2 \mathrm{ml})$ and $\mathrm{CH}_{2} \mathrm{Cl}_{2}(0.02 \mathrm{ml})$ and the flask was wrapped in aluminum foil to protect from light. $\mathrm{AgNO}_{3} / \mathrm{SiO}_{2}$ was added and the reaction was stirred for 2 hours. The reaction was filtered through Celite and concentrated and the residue was purified by chromatography $\left(\mathrm{SiO}_{2}, \mathrm{CH}_{2} \mathrm{Cl}_{2}\right)$. The purified material was dissolved in $\mathrm{MeOH}$ $(0.5 \mathrm{ml})$ and $\mathrm{KCN}(1 \mathrm{mg}, 0.02 \mathrm{mmol})$ was added to the reaction. After 20 minutes, the reaction was diluted with $\mathrm{Et}_{2} \mathrm{O}(5 \mathrm{ml})$ and washed with water $(1 \mathrm{ml})$. The organic layer was dried over $\mathrm{MgSO}_{4}$, concentrated, and purified by chromatography $\left(\mathrm{SiO}_{2}, 20 \%\right.$ acetone $\left./ \mathrm{CH}_{2} \mathrm{Cl}_{2}\right)$. The purified material was dissolved in freshly distilled $\mathrm{CH}_{3} \mathrm{CN}(5 \mathrm{ml})$ and washed with hexanes $(5 \mathrm{X} 2 \mathrm{ml})$. The $\mathrm{CH}_{3} \mathrm{CN}$

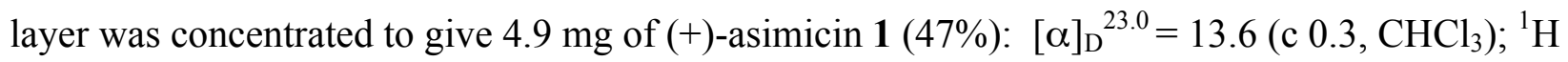
NMR (400 MHz, $\left.\mathrm{CDCl}_{3}\right) \square 7.18(\mathrm{~d}, J=1 \mathrm{~Hz}, 1 \mathrm{H})$, 5.09-5.02 (m, 1H), 3.91-3.80 (m, 5H), 3.43-3.35 (m, 2H), 2.52 (d, J = 15.2 Hz, 1H), 2.43 (bs, 2H), 2.39 (dd, J = 15.2, 8.0 Hz, 1H), 2.24 (bs, 1H), 2.02-1.91 (m, 4H), 1.74-1.58 (m, 4H), 1.56-1.22 (m, 41H), $0.87(\mathrm{t}, J=7.2 \mathrm{~Hz}, 3 \mathrm{H}) ;{ }^{13} \mathrm{C}$ NMR $(100$ $\left.\mathrm{Mhz}, \mathrm{CDCl}_{3}\right) \square 151.8,151.8,131.2,83.1,81.8,78.0,74.1,70.0,69.9,37.4,33.4,33.3,29.9,29.7$, 29.7, 29.6, 29.5, 29.3, 29.0, 28.4, 25.6, 25.6, 25.5, 22.7, 19.1, 14.1; IR (thin film) 3436, 2929, 2854, 1753, 1465, 1319. 1068, 953, $668 \mathrm{~cm}^{-1}$; HRMS calcd for $\mathrm{C}_{37} \mathrm{H}_{66} \mathrm{O}_{7}, 645.4706 \mathrm{~m} / z(\mathrm{M}+\mathrm{Na})^{+}$; observed $645.4720 \mathrm{~m} / \mathrm{z}$.

\section{Comparison of Published ${ }^{1}$ H NMR Data for Synthetic Asimicin}

\begin{tabular}{|l|l|l|}
\hline Sinha \& Keinan & Mc & Marshall \\
\hline $7.17(\mathrm{~s}, 1 \mathrm{H})$ & $7.18(\mathrm{bs}, 1 \mathrm{H})$ & $7.18(\mathrm{~d}, \mathrm{~J}=1 \mathrm{~Hz}, 1 \mathrm{H})$ \\
\hline $5.06-5.01(\mathrm{q}, \mathrm{J}=6.6 \mathrm{~Hz}, 1 \mathrm{H})$ & $5.06(\mathrm{q}, \mathrm{J}=7.7 \mathrm{~Hz}, 1 \mathrm{H})$ & $5.06(\mathrm{q}, \mathrm{J}=6.4 \mathrm{~Hz}, 1 \mathrm{H})$ \\
\hline $3.84-3.80(\mathrm{~m}, 5 \mathrm{H})$ & $3.91-3.79(\mathrm{~m}, 5 \mathrm{H})$ & $3.91-3.80(\mathrm{~m}, 5 \mathrm{H})$ \\
\hline $3.40-3.34(\mathrm{~m}, 2 \mathrm{H})$ & $3.39(\mathrm{q}, \mathrm{J}=5.0 \mathrm{~Hz}, 1 \mathrm{H})$ & $3.43-3.35(\mathrm{~m}, 2 \mathrm{H})$ \\
\hline $2.52-2.48(\mathrm{~d}, \mathrm{~J}=?, 1 \mathrm{H})$ & $2.54(\mathrm{~d}, \mathrm{~J}=15.0 \mathrm{~Hz}, 1 \mathrm{H})$ & $2.52(\mathrm{~d}, \mathrm{~J}=15.2 \mathrm{~Hz}, 1 \mathrm{H})$ \\
\hline & $2.45-2.34(\mathrm{~m}, 1 \mathrm{H})$ & $2.43(\mathrm{bs}, 2 \mathrm{H})$ \\
\hline $2.40-2.34(\mathrm{~d}, \mathrm{~J}=?, 1 \mathrm{H})$ & $2.11(\mathrm{vbs}, 3 \mathrm{H})$ & $2.39(\mathrm{dd}, \mathrm{J}=15.2,8.0 \mathrm{~Hz}, 1 \mathrm{H})$ \\
\hline & $2.04-1.91(\mathrm{~m}, 2 \mathrm{H})$ & $2.24(\mathrm{bs}, 1 \mathrm{H})$ \\
\hline $1.96-1.94(\mathrm{~m}, 4 \mathrm{H})$ & $1.74-1.59(\mathrm{~m}, 4 \mathrm{H})$ & $2.02-1.91(\mathrm{~m}, 4 \mathrm{H})$ \\
\hline & $1.43(\mathrm{q}, \mathrm{J}=6.9 \mathrm{~Hz}, 1 \mathrm{H})$ & $1.74-1.58(\mathrm{~m}, 4 \mathrm{H})$ \\
\hline $1.75-1.23(\mathrm{~m}, 48 \mathrm{H})$ & $1.53-1.19(\mathrm{~m}, 41 \mathrm{H})$ & $1.56-1.22(\mathrm{~m}, 41 \mathrm{H})$ \\
\hline $0.85(\mathrm{t}, \mathrm{J}=6.6 \mathrm{~Hz}, 3 \mathrm{H})$ & $0.88(\mathrm{t}, \mathrm{J}=6.9 \mathrm{~Hz}, 1 \mathrm{H})$ & $0.87(\mathrm{t}, \mathrm{J}=7.2 \mathrm{~Hz}, 3 \mathrm{H})$ \\
\hline
\end{tabular}




\section{Comparison of Published ${ }^{13}$ C NMR Data for Synthetic Asimicin}

\begin{tabular}{|l|l|l|l|}
\hline Isolation $^{8 c}$ & Marshall $^{\text {3d }}$ & Roush (this study) & Carbon Number \\
\hline 174.6 & --- & --- & 1 \\
\hline 151.8 & 151.7 & 151.8 & 35 \\
\hline 131.1 & --- & 131.2 & 2 \\
\hline 83.1 & 83.1 & 83.1 & 16,23 \\
\hline 81.8 & 81.8 & 81.8 & 19,20 \\
\hline 78.0 & 79.9 & 78.0 & 36 \\
\hline 74.0 & 74.1 & 74.1 & 15,24 \\
\hline 69.9 & 70.0 & 70.0 & 4 \\
\hline 37.4 & 37.4 & 37.4 & 3 \\
\hline 33.4 & 33.4 & 33.4 & 14 \\
\hline 33.3 & 33.3 & 33.3 & 25 \\
\hline 31.9 & 31.9 & 31.9 & 5 \\
\hline 29.7 & --- & 29.7 & 32 \\
\hline 29.6 & 29.6 & 29.6 & $26-30$ \\
\hline 29.5 & 29.5 & 29.5 & $7-13$ \\
\hline 29.3 & 29.3 & 29.3 & 31 \\
\hline 28.9 & 29.0 & 29.0 & 6 \\
\hline 28.4 & 28.4 & 28.4 & 17 \\
\hline 25.5 & 25.6 & 25.6 & $18,21,22$ \\
\hline 22.7 & 22.7 & 22.7 & 33 \\
\hline 19.1 & 19.1 & 19.1 & 37 \\
\hline 14.1 & 14.1 & 14.1 & 34 \\
\hline
\end{tabular}

Comparison of Published ${ }^{1}$ H NMR Data for Mosher Ester Derivatives of Synthetic Asimicin

\begin{tabular}{|l|l|l|l|l|}
\hline $\begin{array}{l}\text { Roush - } \\
\text { Observed for } \\
\text { (S)-Ester }\end{array}$ & $\begin{array}{l}\text { Literature } \\
\text { Value for (S)- } \\
\text { Mosher Esters }^{8 d}\end{array}$ & Carbon Number & $\begin{array}{l}\text { Literature } \\
\text { Value for (R)- } \\
\text { Mosher Esters }\end{array}$ & $\begin{array}{l}\text { Roush - } \\
\text { Observed for } \\
\text { (R)-Ester }\end{array}$ \\
\hline 2.57 & 2.56 & 3 & $2.66,2.58$ & $2.65,2.58$ \\
\hline Not clear & 1.63 & 5 & 1.61 & Not clear \\
\hline 1.57 & 1.56 & 14,25 & 1.45 & 1.46 \\
\hline 3.93 & 3.93 & 16,23 & 3.97 & 3.98 \\
\hline 3.77 & 3.76 & 19,20 & 3.92 & 3.92 \\
\hline 6.71 & 6.70 & 35 & 6.96 & 6.96 \\
\hline 4.84 & 4.84 & 36 & 4.88 & 4.88 \\
\hline 1.27 & 1.26 & 37 & 1.29 & 1.30 \\
\hline
\end{tabular}

